\title{
Manifestaciones clínicas de la COVID-19
}

\author{
Clinical manifestations of COVID-19
}

\author{
Karina Julieta Romo Domínguez,* Elsa Gabriela Saucedo Rodríguez,* \\ Sarahi Hinojosa Maya,* Juana Yagleiry Mercado Rodríguez, ${ }^{*}$ Jesús Eduardo Uc Rosaldo, ${ }^{*}$ Elieth Ochoa García, ${ }^{\ddagger}$ \\ Wilver Madrid Mejía, ${ }^{\S}$ Alejandra Olmedo Jiménez," Rosangela Del Razo Rodríguez," \\ Emma Rosario García Colín, ${ }^{* *}$ José Roberto Velázquez Serratos, ${ }^{\#}$ Brenda Aidé Avilés Ramírez, ${ }^{\S \S}$ \\ Irma Lechuga Trejo, ${ }^{\text {"1 }}$ Laura Graciela Gochicoa Rangel,***

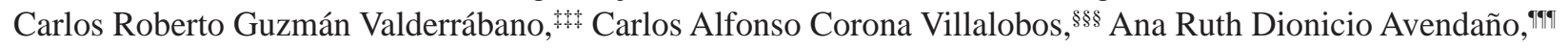 \\ Angélica Cecilia Monsiváis Orozco,**** Leticia Munive Báez, \\ Alba Lucía Rojas, ${ }^{\S \S \S}$ Tania Padilla Benítez ${ }^{\text {ๆqศๆ }}$ \\ * Pediatra. Médico Residente de Neumología Pediátrica, INER. \\ ${ }^{\ddagger}$ Neumólogo Pediatra. Médico Residente de Alta Especialidad en Broncoscopia Pediátrica, INER. \\ ${ }^{\S}$ Residente de Alta Especialidad de Fisiología Pulmonar, INER. \\ "Médico Residente de Cardiología Pediátrica, INP. \\ I Neumólogo y Broncoscopista Pediatra. Médico adscrito de Neumología Pediátrica, INER. \\ ${ }^{* \star}$ Neumólogo y Somnólogo Pediatra. Médico adscrito de Neumología Pediátrica, INER. \\ ¥ Neumólogo. Médico adscrito de Neumología Pediátrica, INER. \\ $\$ \S$ Neumólogo y Broncoscopista Pediatra. Médico adscrito a Neumología Pediátrica, Centro Médico Naval. \\ १ึ Fisiólogo y Neumólogo Pediatra. Médico adscrito de Neumología Pediátrica, Hospital Pediátrico de Ixtapaluca. \\ ***Fisiólogo y Neumólogo Pediatra. Jefe de servicio de Fisiología Pulmonar, INER. \\ \#\#‡Fisiólogo y Neumólogo Pediatra. Médico adscrito al Laboratorio de Fisiología Pulmonar, INER. \\ $\$ \$$ Cardiólogo y Hemodinamista Intervencionista. Médico adscrito a Cardiología Pediátrica, INP. \\ ศศศ Gastroenterólogo Pediatra. Médico adscrito a Pediatría del Hospital General «Dr. Manuel Gea González».

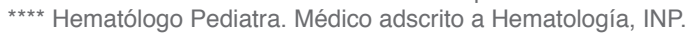

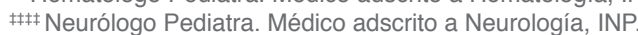 \\ \$\$\&§ Pediatra, Médico Residente de Neumología Pediátrica, INER. \\ ศศศগ Dermatólogo Pediatria, Hospital Médica Sur.
}

El espectro clínico de SARS-CoV-2 varía de formas asintomáticas o paucisintomáticas a condiciones clínicas caracterizadas por insuficiencia respiratoria que necesite ventilación mecánica y soporte en la UTI con manifestaciones sistémicas como sepsis, choque séptico, falla orgánica múltiple..$^{1,2}$

En comparación con población adulta, el número de pacientes pediátricos confirmados es bajo $(2 \%$ en menores de 19 años) al igual que la gravedad y mortalidad. ${ }^{3,4}$ Las muertes reportadas a nivel mundial suceden entre 10 y 19 años de edad (adolescentes principalmente) y casos de enfermedad grave princi-

Financiamiento: Ninguno.

Conflicto de intereses: Ninguno.

Rev Latin Infect Pediatr 2020; 33 (s1): s10-s32 palmente en menores de un año, los cuales suponen población de alto riesgo de enfermedad grave. ${ }^{5,6}$

Los niños con infección por SARS-CoV-2 pueden cursar con enfermedad leve o asintomática en $81 \%$, progresando a grave en $14 \%$ y crítica en $5 \%$ complicándose principalmente con SDRA o insuficiencia respiratoria. También se ha reportado choque séptico, encefalopatía, acidosis metabólica, lesión miocárdica o insuficiencia cardiaca, trastornos de coagulación, lesión renal aguda y falla multiorgánica que pueden ser mortales. 7,8 Dichas complicaciones asociadas se pueden explicar debido a que el SARS-CoV-2

Citar como: Romo DKJ, Saucedo REG, Hinojosa MS, Mercado RJY, Uc RJE, Ochoa GE et al. Manifestaciones clínicas de la COVID-19. Rev Latin Infect Pediatr. 2020; 33 (s1): s10-s32. https://dx.doi.org/10.35366/96668 
Rev Latin Infect Pediatr 2020; 33 (s1): s10-s32

se une con gran afinidad a la enzima convertidora de angiotensina 2 (ACE 2), que es utilizada como receptor de entrada para invadir las células; encontrándose receptores de ACE 2 en diferentes órganos como la superficie de los neumocitos tipo II, intestino, corazón, riñón, cerebro y placenta, lo que explica el daño multiorgánico que se puede presentar. ${ }^{9}$

El bajo porcentaje de complicaciones en población pediátrica se puede explicar por diversos factores: se especula que la maduración y función (p. ej. capacidad de unión) de la ACE 2 es menor en niños que en adultos; además los niños tienen más infecciones respiratorias virales en invierno, confiriéndoles más títulos de anticuerpos frente a éstos, entre otros. ${ }^{10} \mathrm{La}$ información presentada a continuación se basa principalmente en datos obtenidos en población adulta, pero que es posible evaluar de manera individual si puede ser aplicable a pediatría.

\section{A. DEFINICIONES OPERACIONALES Y CLASIFICACIÓN DE GRAVEDAD}

A continuación presentamos las principales definiciones que pueden ser aplicables en nuestro medio y en nuestro país, con reserva de que se modificarán conforme el paso del tiempo, con base en estudios que realizan las instituciones oficiales.

\section{Caso sospechoso}

a) Persona de cualquier edad que resida en México o haya viajado a un país con transmisión local de la enfermedad que en los últimos siete días haya presentado al menos dos de los siguientes signos y síntomas: tos, fiebre o cefalea, acompañadas de al menos uno de los siguientes signos o síntomas: disnea, mialgias, cefalea, artralgias, odinofagia, rinorrea, anosmia o hiposmia, conjuntivitis, dolor torácico, síntomas gastrointestinales como diarrea, vómito, o dolor abdominal. En el INER recomendamos considerar síntomas gastrointestinales (náusea, vómito, diarrea), anosmia e hiposmia dentro de la definición de caso sospechoso por los reportes generados en otros países. ${ }^{11-13}$

b) Paciente con enfermedad respiratoria aguda y antecedente de contacto con un caso confirmado de COVID-19 en los últimos 14 días previos al inicio de los síntomas. ${ }^{14}$

c) Paciente con enfermedad respiratoria aguda grave (fiebre y al menos un signo o síntomas de enfermedad respiratoria como tos, disnea) que requiera hospitalización, sin otro diagnóstico que explique la presentación clínica. ${ }^{14}$

\section{Caso probable}

a) Un caso sospechoso cuya prueba para SARSCoV-2 resultó inconclusa. ${ }^{14}$

b) Un caso sospechoso en el que no puede realizarse la prueba para SARS-CoV-2 por cualquier razón, con hallazgos tomográficos característicos de neumonía por SARS-CoV-2 como patrón de vidrio despulido, patrón en empedrado, patrón de consolidación, con localización

Tabla 1: Clasificación de gravedad de la COVID-19 según la AAP.

Infección asintomática

Enfermedad leve

Enfermedad moderada

Enfermedad grave

Enfermedad crítica
Paciente sin síntomas ni signos clínicos, radiografía normal y PCR positiva para SARS-CoV-2 Presentan síntomas de vía respiratoria superior, además de fiebre, fatiga, mialgia, tos, escurrimiento nasal. Al examen físico se encuentra congestión faríngea, sin datos anormales a la auscultación. Algunos casos pueden estar afebriles o con síntomas digestivos como náusea, dolor abdominal o diarrea

Con neumonía, frecuentemente fiebre, tos que en la mayoría de los casos es de inicio seca, seguida de tos productiva; en algunas ocasiones con disnea, sin datos de hipoxemia, se pueden auscultar crepitantes; otros casos no tienen signos o síntomas clínicos; sin embargo, la tomografía computarizada muestra lesiones pulmonares que son subclínicas

Tempranamente presentan síntomas como fiebre y tos, quizá acompañada de síntomas gastrointestinales como diarrea La enfermedad usualmente progresa en alrededor de una semana con disnea y cianosis central, la $\mathrm{SpO}_{2}$ es menor de $92 \%$ con manifestaciones de hipoxemia

Además de los síntomas de enfermedad grave puede progresar rápidamente a SDRA y choque, encefalopatía, daño miocárdico, disfunción de la coagulación y daño renal

$\mathrm{AAP}=$ American Academy of Pediatrics; $\mathrm{PCR}=$ siglas en inglés de reacción en cadena de la polimerasa; $\mathrm{SpO}_{2}=$ saturación de oxígeno; $\mathrm{SDRA}=$ síndrome de dificultad respiratoria aguda. 
principalmente a nivel subpleural y de manera bilateral. ${ }^{14-16}$

\section{Caso confirmado}

Persona que cumpla con la definición operacional de caso sospechoso y que cuente con diagnóstico confirmado por laboratorio emitido por el InDRE. ${ }^{11}$

\section{Contacto}

Persona con exposición dentro de los dos días previos y hasta 14 días posteriores al inicio de los síntomas con un caso probable o confirmado en los siguientes escenarios:

a) Contacto cara a cara con un caso probable o confirmado a 1 metro y por más de 15 minutos.

b) Contacto físico directo con un caso probable o confirmado.

c) Cuidador de un paciente probable o confirmado de COVID-19 sin uso de EPP. ${ }^{14,17}$

\section{Espectro clínico de manifestaciones asociadas a infección por SARS-CoV-2 (COVID-19)}

La Asociación Americana de Pediatría ${ }^{10}$ clasifica la gravedad de SARS-CoV-2 por los hallazgos clínicos, laboratorio y de imagen en: infección asintomática, infección no complicada, leve, moderada, grave y casos críticos como se muestra en la Tabla 1.

La infección causada por el virus SARS-CoV-2 tiene un espectro amplio de presentación tanto en adultos como en niños, el cual incluye desde la presentación de un paciente asintomático hasta un cuadro grave con SDRA, sepsis, choque séptico y muerte. ${ }^{18}$

Infección no complicada: se presenta con síntomas inespecíficos como fiebre, tos (seca o productiva), odinofagia, congestión nasal, anosmia, hiposmia, malestar general, anorexia, cefalea, mialgias. Los pacientes inmunosuprimidos pueden presentar síntomas atípicos, sin datos de deshidratación, sepsis o dificultad respiratoria. ${ }^{12,13,18,19}$

Infección leve de vías respiratorias bajas: tos, dificultad respiratoria con taquipnea (Tabla 2), desaturación, puede o no haber fiebre, sin signos de infección grave de vías respiratorias.

Desaturación se entiende como $<90 \%$ en la Ciudad de México, $<92 \%$ a nivel del mar.

\begin{tabular}{|cc|}
$\begin{array}{c}\text { Tabla 2: Rango a partir del cual se considera } \\
\text { taquipnea en los diferentes grupos etarios. }\end{array}$ \\
\hline Edad & Frecuencia respiratoria (RPM) \\
\hline$<2$ meses & $\geq 60$ \\
$2-11$ meses & $\geq 50$ \\
$1-5$ años & $\geq 40$ \\
Adultos/adolescentes & $>30$ \\
\hline RPM = respiraciones por minuto. \\
Tomado de: OMS y Calvo-Rey M. ${ }^{18,19}$ \\
\end{tabular}

Infección grave de vías respiratorias bajas: tos, dificultad respiratoria y al menos uno de los siguientes datos: ${ }^{18,19}$

- Cianosis central o desaturación.

- Dificultad respiratoria: quejido, aleteo nasal, tiraje supraesternal, retracción torácica severa o disociación toracoabdominal.

- Taquipnea.

- Dificultad para la alimentación.

- Disminución del estado de alerta: letargo, pérdida de conocimiento o crisis convulsivas.

- Gasometría arterial: $\mathrm{PaO}_{2}<60 \mathrm{mmHg}, \mathrm{PaCO}_{2}>$ $50 \mathrm{mmHg}$.

La radiografía de tórax se realiza como apoyo diagnóstico para exclusión de complicaciones.

En estos casos debemos buscar otras manifestaciones de gravedad como:

- Trastornos de coagulación: prolongación de tiempo de protrombina.

- Daño miocárdico: elevación de enzimas cardiacas, cambios electrocardiográficos, cardiomegalia, insuficiencia cardiaca.

- Disfunción gastrointestinal.

- Elevación de enzimas hepáticas.

- Rabdomiólisis.

- Insuficiencia renal*.

\section{Criterios diagnósticos de SDRA: :,18,19}

- Síntomas respiratorios agudos, o empeoramiento del cuadro de tos en los 10 días previos.

\footnotetext{
En el INER recomendamos realizar valoración de función renal a todo paciente grave desde su ingreso y catalogarse como manifestación de gravedad cualquier alteración en la misma.
} 
Rev Latin Infect Pediatr 2020; 33 (s1): s10-s32

- Presencia de nuevos infiltrados unilaterales/bilaterales por radiografía, tomografía o ultrasonido de tórax.

- Cambios no asociados con sobrecarga de volumen o insuficiencia cardiaca.

- Oxigenación:

- VNI binivel o CPAP > $5 \mathrm{cmH}_{2} \mathrm{O}$ a través de una máscara facial completa: $\mathrm{PaO}_{2} / \mathrm{FiO}_{2}<300$ $\mathrm{mmHg} \circ \mathrm{SpO}_{2} / \mathrm{FiO}_{2}<264$.

- SDRA leve: $4<10<8,<5$ ISO $<7.5$.

- SDRA moderado: $8<10<16,7.5<$ ISO $<12.3$.

- SDRA grave: $I O>16$, ISO > 12.3.

- En caso de pacientes adolescentes considerar clasificación y manejo por las definiciones de Berlín:

- SDRA leve: $200 \mathrm{mmHg}<\mathrm{PaO}_{2} / \mathrm{FiO}_{2}<300$ $\mathrm{mmHg}$ con PEEP O CPAP $>5 \mathrm{mmHg}$ o sin ventilación mecánica.

- SDRA moderado: $100 \mathrm{mmHg}<\mathrm{PaO}_{2} / \mathrm{FiO}_{2}<$ $200 \mathrm{mmHg}$ con PEEP $>5 \mathrm{mmHg}$ o sin ventilación mecánica.

- SDRA grave: $\mathrm{PaO}_{2} / \mathrm{FiO}_{2}<100 \mathrm{mmHg}$ con PEEP o CPAP > $5 \mathrm{mmHg}$ o sin ventilación mecánica.

- En caso de no contar con $\mathrm{PaO}_{2}, \mathrm{SpO}_{2} / \mathrm{FiO}_{2}<$ 315, sugiere SDRA. ${ }^{\ddagger}$

Criterios diagnósticos de sepsis: ${ }^{7,18-20}$ infección sospechada o comprobada y $>2$ criterios de SRIS, de los cuales uno debe ser alteración de temperatura o recuento leucocitario anormal, los otros dos criterios son taquipnea y taquicardia o bradicardia en $<$ un año.

Criterios diagnósticos de sepsis grave: $:^{7,18-20}$ disfunción cardiovascular, SDRA $0 \geq 2$ disfunciones del resto de órganos.

Criterios diagnósticos de choque séptico: ${ }^{7,18-20}$

Hipotensión (< percentil 5 o > 2 DE por debajo de lo normal para la edad) o de dos a tres de los siguientes:

- Alteración del estado mental (irritabilidad, somnolencia).

- Taquicardia o bradicardia (Tabla 3).

- Llenado capilar retardado (>2 segundos) o vasodilatación caliente con pulsos conservados.

- Taquipnea.

- Piel moteada o erupción petequial o purpúrica.

- Elevación de lactato $>2 \mathrm{mmol} / \mathrm{L}$.

A altitudes superiores a 1,000 m debe calcularse el factor de corrección de la siguiente manera: $\mathrm{PaO}_{2} / \mathrm{FiO}_{2} \times$ presión barométrica/760.
- Oliguria: lactantes $<0.5 \mathrm{~mL} / \mathrm{kg} / \mathrm{h}$, mayores de dos años $<1 \mathrm{~mL} / \mathrm{kg} / \mathrm{h}$ o $<12 \mathrm{~mL} / \mathrm{m}^{2} \mathrm{SC} / \mathrm{h}$.

- Hipertermina o hipotermia (temperatura $\langle 36$ o $>$ $\left.37.9^{\circ} \mathrm{C}\right)$.

Es importante definir otras complicaciones que se pueden presentar en pacientes con COVID-19, ya que aunque no se encuentran en la clasificación de gravedad del paciente, sí impactan en el pronóstico:

- EI SDRA y el choque se definen de acuerdo con las guías de la OMS como se menciona en el capítulo de definiciones operacionales de la enfermedad. ${ }^{21}$

- La falla renal aguda se identifica por los niveles séricos de creatinina elevados.

- La infección secundaria se presenta con signos o síntomas de neumonía nosocomial o bacteremia con un cultivo positivo de vía respiratoria inferior (incluyendo expectoración, aspirado traqueal o lavado broncoalveolar o muestra de sangre) después de 48 horas de admisión. ${ }^{21}$

- La lesión cardiaca se define con biomarcadores cardiacos séricos (troponina I) arriba del percentil 99 para la edad, o de anormalidades mostradas en el electrocardiograma o en ecocardiograma. ${ }^{1,10}$

Se ha demostrado que los niños que tienen enfermedades subyacentes tienden a progresar a enfermedad grave y casos críticos, por lo que debemos poner atención a estos grupos con estrecha supervisión. Sin embargo, la mayor presencia de comorbilidades como diabetes, hipertensión, enfermedad arterial coronaria en más de $50 \%$ de los adultos afectados por SARS-CoV-2 ocasiona que la población adulta sea más susceptible a mayor riesgo de enfermedad grave. ${ }^{22}$

Hasta el momento, es importante que se clasifique a los pacientes por gravedad para otorgar tratamiento

Tabla 3: Frecuencia cardiaca para considerar bradicardia y taquicardia, según el grupo etario.

\begin{tabular}{lcc} 
& Bradicardia (LPM) & Taquicardia (LPM) \\
\hline Lactantes & $<90$ & $>160$ \\
Niños & $<70$ & $>150$ \\
\hline LPM = latidos por minuto. &
\end{tabular}


adecuado, incluso si los pacientes no tienen pruebas positivas iniciales, ya que en algunos casos se requiere repetir la prueba en dos o tres ocasiones, debido a los falsos negativos. Para los casos negativos con alta sospecha se sugiere muestras continuas para mejorar la sensibilidad, ${ }^{23}$ según disponibilidad de pruebas en la institución. En un estudio de 51 pacientes, la primera muestra respiratoria resultó positiva en $70 \%$, adicional en segunda prueba de $24 \%$ (acumulada de $94 \%$ ), y un adicional de $3.9 \%$ (98\% acumulado) en tercera prueba. ${ }^{24}$

En el estudio de pacientes de Dong Y y colaboradores con clasificación por gravedad, $5.2 \%$ tenían enfermedad grave y $0.6 \%$ enfermedad crítica. La enfermedad grave se definía como disnea, cianosis central y saturación de oxígeno $\left(\mathrm{SpO}_{2}\right)$ menor de $92 \%$; y la enfermedad crítica con falla respiratoria y en algunas ocasiones con choque, signos de falla multiorgánica como encefalopatía, falla cardiaca, alteraciones de la coagulación y/o falla renal. ${ }^{10}$

De 2,193 pacientes pediátricos estudiados en la provincia de Wuhan, China, la prevalencia de gravedad y enfermedad crítica es de $10.6 \%$ en menores de un año, de uno a cinco años de $7.3 \%$, de seis a 10 años de $4.2 \%$, de 11 a 15 años de $4.1 \%$ y de 16 a 17 años de $3 \%$. La mitad de los niños con enfermedad crítica por COVID-19 en este estudio eran menores de un año. ${ }^{10}$

De los 171 niños tratados en el hospital pediátrico de Wuhan, tres (1.8\%) requirieron de terapia intensiva y fallecieron: uno presentó hidronefrosis, otro niño falleció posterior a quimioterapia por leucemia y otro por intususcepción. ${ }^{10}$

En los brotes detectados en otros países se han observado cifras diferentes a las notificadas en China, siendo mayores en algunos países como Irán al comienzo del brote y menores en otros como Corea del Sur o Singapur, lo que puede responder a diferencias en la sensibilidad de los sistemas de vigilancia de cada país. El porcentaje de admisión hospitalaria en Estados Unidos de América por SARS-CoV-2 fue de $1.6-2.5 \%{ }^{23}$

\section{B. CRITERIOS DE HOSPITALIZACIÓN Y TERAPIA INTENSIVA}

Un pequeño porcentaje de los pacientes pediátricos sintomáticos requerirá hospitalización y uno todavía menor requerirá ingreso a terapia intensiva. ${ }^{25}$ Por lo anterior, es importante identificar qué pacientes tienen mayor riesgo de desarrollar enfermedad
Tabla 4: Factores de riesgo de mal pronóstico.

$\begin{array}{ll}\text { Inmunodepresión } & \text { Inmunodeficiencias primarias } \\ & \text { Trasplante órgano sólido y trasplante } \\ & \text { progenitores hematopoyéticos } \\ & \text { Tratamiento con quimioterapia, inmunosu- } \\ & \text { presores o fármacos biológicos } \\ & \text { VIH mal controlado (carga viral detectable, } \\ & \text { disminución CD4 o inversión cociente } \\ & \text { CD4/CD8) } \\ \text { Cardiopatías } & \text { Con repercusión hemodinámica } \\ & \text { Precisan tratamiento médico } \\ & \text { Hipertensión pulmonar } \\ & \text { En lista de espera de trasplante } \\ & \text { Postoperatorio reciente de cirugía o } \\ & \text { cateterismo } \\ \text { Patología } & \text { Fibrosis quística } \\ \text { respiratoria } & \text { Displasia broncopulmonar } \\ \text { crónica } & \text { Asma grave } \\ & \text { Portadores de traqueostomía, oxigenoterapia } \\ & \text { o ventilación mecánica domiciliaria } \\ & \text { Desnutrición } \\ \text { Otros } & \text { Diálisis } \\ & \text { Drepanocitosis } \\ & \text { DM tipo 1 con mal control metabólico } \\ & \text { Malnutrición severa } \\ \text { Intestino corto } \\ \text { Epidermólisis bullosa } \\ \text { Encefalopatías graves } \\ \text { Miopatías } \\ \text { Errores congénitos del metabolismo } \\ \end{array}$

Modificado de: Documento de manejo clínico del paciente pediátrico con infección por SARS-CoV-2. Asociación Española de Pediatría (AEP). ${ }^{18}$

grave, ya que deberán tener una vigilancia más estrecha en el medio hospitalario. 7,18

Los criterios de hospitalización son pacientes que cumplan con definición operacional de caso sospechoso más alguna condición de las siguientes:

- Edad menor de un mes con fiebre y habiendo descartado otras enfermedades no respiratorias.

- Edad de uno a tres meses con algún dato de infección de vías respiratorias bajas.

- Pacientes con cualquier factor de riesgo (Tabla 4).

- Pacientes de cualquier edad con criterios de infección grave de vías respiratorias bajas.

- Hipoxemia $\left(\mathrm{PaO}_{2}<60 \mathrm{mmHg}\right.$ en gasometría arterial) o dificultad respiratoria que no mejora tras tratamiento broncodilatador.

- Mal estado general, letargia. 
- Rechazo a la alimentación.

- Apneas.

\section{Criterios de ingreso a Unidad de Cuidados Intensivos Pediátricos ${ }^{7,18}$}

- Polipnea o dificultad respiratoria persistente a pesar de optimizar tratamiento.

- $\mathrm{SpO}_{2}<90 \%$ con $\mathrm{FiO}_{2}>0.5$ (con mascarilla reservorio).

- Acidosis respiratoria aguda $\left(\mathrm{PCO}_{2}<55 \mathrm{mmHg}\right.$ y/o $\mathrm{pH}<7.30$ ).

- Apneas recurrentes.

- Aspecto séptico, signos de choque, falla orgánica múltiple.

- Alteración del nivel de conciencia o sospecha de fallo de centro respiratorio (hipoventilación central).

\section{MANIFESTACIONES CLÍNICAS}

Los informes en diferentes países indican que los niños son menos afectados por COVID-19 y cuando desarrollan enfermedad, rara vez progresan a un estado grave. ${ }^{26}$ En China, $2.4 \%$ de la población infectada fueron niños; en Italia 1.4\% sin registrarse muertes, en Australia $5.6 \%$ y en Corea $6.2 \% .{ }^{27}$

Resulta importante destacar que $56 \%$ de los pacientes pediátricos infectados tenían el antecedente de contacto con enfermos en casa. ${ }^{27}$ Hasta ahora no se ha documentado la transmisión vertical SARS-CoV-2 y se ha informado que la enfermedad en recién nacidos ocurre raramente. ${ }^{28}$

Un gran número de pacientes pediátricos se mantienen asintomáticos, pero pueden eliminar

Tabla 5: Presentación y estadio clínico de los pacientes con infección por SARS-CoV-2.

\begin{tabular}{|c|c|c|c|c|}
\hline Estadio clínico & $\begin{array}{l}\text { Porcentaje de } \\
\text { presentación }\end{array}$ & Síntomas & Exploración física & Auxiliares diagnósticos \\
\hline Asintomático & 13.0 & Sin síntomas clínicos & Normal & $\begin{array}{l}\text { Radiografía normal, RT-PCR } \\
\text { positiva }\end{array}$ \\
\hline Leve & 43.0 & $\begin{array}{l}\text { Síntomas de infección de vías } \\
\text { aéreas superiores: } \\
\text { - odinofagia } \\
\text { - rinorrea } \\
\text { - estornudos } \\
\text { - congestión nasal } \\
\text { - fiebre de baja intensidad } \\
\text { - mialgias } \\
\text { - tos seca } \\
\text { - } \text { síntomas digestivos leves }\end{array}$ & $\begin{array}{l}\text { Hiperemia en mucosa } \\
\text { nasal y faríngea }\end{array}$ & $\begin{array}{l}\text { Radiografía normal, RT-PCR } \\
\text { positiva. Cambios tomográficos } \\
\text { en } 35 \%\end{array}$ \\
\hline Moderado & 41.0 & $\begin{array}{l}\text { - fiebre } \\
\text { - tos húmeda } \\
\text { - fatiga } \\
\text { - cefalea } \\
\text { - sibilancias }\end{array}$ & $\begin{array}{l}\text { Estertores gruesos, } \\
\text { oximetría conservada }\end{array}$ & $\begin{array}{l}\text { Tomografía de tórax con lesio- } \\
\text { nes características }\end{array}$ \\
\hline Grave & 2.5 & $\begin{array}{l}\text { - fiebre } \\
\text { - tos con disnea } \\
\text { - síntomas gastrointestinales } \\
\text { (diarrea) } \\
\text { - taquipnea } \\
\text { - dificultad respiratoria }\end{array}$ & Hipoxemia & $\begin{array}{l}\text { Elevación de enzimas } \\
\text { hepáticas, } \\
\text { rabdomiólisis, } \\
\text { alteraciones en la coagulación }\end{array}$ \\
\hline Crítico & 0.4 & $\begin{array}{l}\text { Insuficiencia respiratoria } \\
\text { aguda que amerita ventilación } \\
\text { mecánica }\end{array}$ & $\begin{array}{l}\text { Choque séptico, } \\
\text { encefalopatía, } \\
\text { falla cardiaca, } \\
\text { coagulación intravascular } \\
\text { diseminada, } \\
\text { insuficiencia renal, } \\
\text { falla multiorgánica }\end{array}$ & $\begin{array}{l}\text { Lo referente a la falla } \\
\text { multiorgánica }\end{array}$ \\
\hline
\end{tabular}




\begin{tabular}{|c|c|c|c|c|c|c|c|c|c|c|c|}
\hline & $\begin{array}{l}\text { Liu et al. } \\
\text { (4) }\end{array}$ & $\begin{array}{l}\text { Cai } \\
\text { et al. }\end{array}$ & $\begin{array}{l}\text { Wei } \\
\text { et al. }\end{array}$ & $\begin{array}{l}\text { Wang } \\
\text { et al. }\end{array}$ & $\begin{array}{l}\text { Feng } \\
\text { et al. }\end{array}$ & $\begin{array}{l}\text { Xia } \\
\text { et al. }\end{array}$ & SPCh & Li et al. & $\begin{array}{l}\text { US } \\
\text { DHHS }\end{array}$ & $\begin{array}{l}\text { Ying } \\
\text { et al. }\end{array}$ & $\begin{array}{l}\text { Haiyan Qiu } \\
\text { et al. }\end{array}$ \\
\hline $\mathrm{N}$ & 6 & 10 & 9 & 31 & 15 & 20 & 134 & 10 & 291 & 7 & 36 \\
\hline Edad (años) & $1-7$ & $0.3-10.9$ & $0.2-0.9$ & $0.5-17$ & $4-14$ & $1-14.6$ & $36 \mathrm{~m}-18$ & $1-17$ & $0-17$ & $0.2-13$ & $0-16$ \\
\hline \multicolumn{12}{|l|}{ Síntomas (\%) } \\
\hline Fiebre & 100 & 80 & 57 & 64.5 & 33.3 & 60 & 76.1 & 40 & 56 & 71.4 & 36 \\
\hline Tos & 100 & 60 & 28.6 & 45.2 & 6.7 & 65 & $\mathrm{NE}$ & 30 & 54 & 71.4 & 19 \\
\hline Rinorrea & 16.7 & 20 & 14.3 & 6.5 & $\mathrm{NE}$ & 15 & $\mathrm{NE}$ & NE & 7.2 & $\mathrm{NE}$ & NE \\
\hline Odinofagia & $\mathrm{NE}$ & 40 & $\mathrm{NE}$ & 6.5 & $\mathrm{NE}$ & 5 & $\mathrm{NE}$ & 0 & 24 & 14.3 & 3 \\
\hline Cefalea & $\mathrm{NE}$ & $\mathrm{NE}$ & $\mathrm{NE}$ & 9.7 & $\mathrm{NE}$ & $\mathrm{NE}$ & NE & 20 & 28 & NE & $\mathrm{NE}$ \\
\hline Diarrea & $\mathrm{NE}$ & 0 & $\mathrm{NE}$ & 9.7 & $\mathrm{NE}$ & 15 & NE & 0 & 13 & 57.1 & NE \\
\hline Disnea & 16.7 & 0 & NE & 0 & $\mathrm{NE}$ & 10 & NE & 0 & 13 & 42.9 & 3 \\
\hline Vómito & $\mathrm{NE}$ & $\mathrm{NE}$ & $\mathrm{NE}$ & $\mathrm{NE}$ & $\mathrm{NE}$ & NE & $\mathrm{NE}$ & 0 & 11 & 57.1 & $\mathrm{NE}$ \\
\hline Mialgias & $\mathrm{NE}$ & $\mathrm{NE}$ & $\mathrm{NE}$ & $\mathrm{NE}$ & $\mathrm{NE}$ & $\mathrm{NE}$ & $\mathrm{NE}$ & $\mathrm{NE}$ & 23 & 0 & $\mathrm{NE}$ \\
\hline $\begin{array}{l}\text { Dolor } \\
\text { abdominal }\end{array}$ & $\mathrm{NE}$ & $\mathrm{NE}$ & $\mathrm{NE}$ & $\mathrm{NE}$ & $\mathrm{NE}$ & $\mathrm{NE}$ & $\mathrm{NE}$ & $\mathrm{NE}$ & 5.8 & $\mathrm{NE}$ & $\mathrm{NE}$ \\
\hline
\end{tabular}

activamente el virus, transmitir la enfermedad y el periodo de incubación puede extenderse hasta 24 días en estos individuos, por lo que resulta importante la identificación de casos. ${ }^{26}$

El CChCPE identificó 2,143 casos en pacientes de 0 a 18 años con un fallecimiento. Los síntomas más comunes fueron fiebre en $65 \%$ y tos en $45 \%$. Sólo $6 \%$ desarrolló enfermedad grave y $11 \%$ eran menores de un año. ${ }^{26}$ De éstos, $13 \%$ eran asintomáticos contribuyendo a la transmisión temprana, incluso documentándose la excreción del virus en las heces de estos niños asintomáticos. ${ }^{28}$ La mortalidad reportada es de $0.18 \% .{ }^{27}$

Los síntomas iniciales más comunes son fiebre $(40 \%)$, febrícula (32\%), seguidas de tos seca (30\%), la cual disminuye al tercer día en $75 \%$ en la población y cefalea (20\%). Otros síntomas son fatiga, odinofagia, mialgias, rinorrea, estornudos, disnea y diarrea. ${ }^{29} \mathrm{La}$ disnea y cianosis pueden ocurrir a medida que la afección progresa, generalmente después de una semana de la enfermedad, acompañadas de síntomas sistémicos, irritabilidad, hiporexia e hipoactividad. Los casos graves desarrollan choque séptico, acidosis metabólica y coagulopatía que puede desencadenar hemorragias así como falla renal aguda. ${ }^{27}$

Los síntomas intestinales (diarrea, dolor abdominal y vómito) del SARS-CoV-2 pueden estar asociados con la invasión de las células epiteliales intestinales que expresan ACE 2. La mayoría de los pacientes que ingresaron a una unidad de cuidados intensivos manifiestan síntomas digestivos asociados con los respiratorios. ${ }^{30}$

Según las características clínicas en los pacientes pediátricos se pueden dividir en cinco grupos como se muestra en la Tabla 5. 10,30,31

Diversos reportes de las características clínicas de los pacientes mencionan que los síntomas más frecuentemente presentados son fiebre y tos s $^{10,22,27,29,32}$ como se comentó previamente y se muestra en la Tabla 6 .

Una posible explicación para la presentación más leve de la enfermedad COVID-19 en niños es que éstos tienen una respuesta cualitativamente diferente al virus del SARS-CoV-2 en comparación con los adultos. Otra posibilidad es que la presencia de otros virus simultáneos en la mucosa de los pulmones y las vías respiratorias, que son comunes en niños pequeños, podría limitar el crecimiento de SARSCoV-2 por interacciones directas de un virus a otro y la competencia. ${ }^{25}$ Otra posible teoría al respecto está relacionada con las diferencias en la expresión del receptor de la ACE 2 necesaria para la unión e infección por SARS-CoV-2 y que se expresa también en los pulmones. ${ }^{25}$

\section{Manifestaciones de vías respiratorias superiores e inferiores}

De acuerdo con la Organización Mundial de la Salud (OMS), cerca de $82 \%$ de los pacientes de COVID- 
Rev Latin Infect Pediatr 2020; 33 (s1): s10-s32

19 tienen síntomas leves y se recuperan inmediatamente. Para el 20 de febrero había alrededor de 18,264 casos recuperados en China. La media de instalación de los síntomas para recuperarse tanto en casos leves como graves fue de entre dos y de tres a seis semanas, respectivamente. El intervalo de tiempo entre el inicio de los síntomas y el desarrollo de síntomas graves como hipoxia fue alrededor de una semana. En los casos fuera de China, el tiempo de recuperación era de 33.5 días. El tiempo desde la instalación de los síntomas hasta la muerte variaba de 20.2 a 22.3 días. ${ }^{33}$

En un estudio de Dong $Y$ y colaboradores se examinó 2,143 niños, $34.1 \%$ tenían enfermedad confirmada por laboratorio, mientras que el resto tenían sospecha clínica. Los síntomas eran típicos de una infección de vías respiratorias e incluían fiebre, tos, odinofagia, estornudos, mialgia y fatiga. ${ }^{10} \mathrm{En}$ otro estudio del hospital de Wuhan se revisaron 171 niños con enfermedad confirmada. El síntoma más común era tos $(48.5 \%)$, eritema faríngeo $(46.2 \%)$ y rinorrea $(7.6 \%){ }^{34}$ En uno de los primeros reportes de la enfermedad, documentaron tos seca $(76 \%){ }^{1}$

Se ha estudiado una presentación atípica de la enfermedad con disfunciones olfatorias y gustativas. Algunas infecciones virales como el rinovirus, virus de Epstein-Barr, parainfluenza y algunos coronavirus pueden producir disfunción olfatoria a través de una reacción inflamatoria de la mucosa nasal y rinorrea. Sin embargo, se ha estudiado disfunción olfatoria y gustativa por SARS-CoV-2 sin congestión nasal ni rinorrea. Los otorrinolaringólogos de la European Federation of Oto-Rhino-Laryngology Societies (EU.F.O.S.) realizaron un estudio epidemiológico para caracterizar los trastornos olfatorios y gustativos en pacientes infectados. En $85.6 \%$ se detectó disfunción olfatoria, de ellos $80 \%$ con hiposmia y $20 \%$ con anosmia que recuperaron la función olfatoria a los ocho días en $67.8 \%$ de los casos. ${ }^{35}$

El estudio de Mao L y su equipo reporta pacientes con síntomas del sistema nervioso periférico atribuidos a la infección por COVID-19, los síntomas más comunes fueron hipogeusia $(5.6 \%)$ e hiposmia (5.1\%). La prevalencia de disfunción olfatoria y gustativa es mayor en pacientes europeos con COVID-19. ${ }^{13}$ Cabe mencionar que la capacidad del coronavirus humano para invadir el bulbo olfatorio y, por lo tanto, el sistema nervioso central es muy importante. Desde el punto de vista biomolecular, los virus podrían infectar neuronas periféricas utilizando la maquinaria celular de transporte activo para acceder al sistema nervioso central. Por lo tanto, el SARS-CoV-2 puede ingresar al cerebro a través del bulbo olfatorio, lo que lleva a diseminación transneuronal rápida. El antígeno del virus se detectó por primera vez entre 60 y 66 horas postinfección y fue más abundante en el bulbo olfatorio. Regiones de la corteza (cortezas piriformes e infralímbicas), ganglios basales (pálido ventral y regiones preópticas laterales), y el mesencéfalo (rafe dorsal) también se detectaron con infección; estas regiones están conectadas con el bulbo olfatorio. La rápida propagación del SARS-CoV-2 en el cerebro también se asoció con una muerte neuronal significativa. ${ }^{36}$

El pulmón es el órgano diana de la infección por SARS-COV-2. Chen $\mathrm{N}$ y colaboradores analizaron retrospectivamente 99 pacientes con enfermedad respiratoria aguda por SARS-CoV-2, de los cuales $76 \%$ recibió oxigenoterapia y $17 \%$ recibió ventilación mecánica. 17 pacientes desarrollaron SDRA, $75 \%$ de los casos desarrollaron neumonía bilateral por tomografía con patrón de llenado y vidrio deslustrado. ${ }^{37} \mathrm{La}$ proteína ACE 2 se encuentra en $1.4 \%$ de las células alveolares tipo II y raramente se presenta en otro tipo de células pulmonares como las células alveolares tipo I, células del epitelio bronquial, células endoteliales, fibroblastos y macrófagos. Li SR y colegas mostraron que bloquear la vía de renina-angiotensina podría disminuir el daño pulmonar grave causado por edema. La deleción del gen ACE 2 también promueve la fibrosis tisular mediada por la vía de señalización TGFb/SMAD y la inflamación mediada por NF-kB. ${ }^{38}$

Finalmente, de los casos estudiados por el CChiCPE, $80.9 \%$ se consideraron leves, $13.8 \%$ graves y $4.7 \%$ críticos. Los casos fatales en pacientes críticos fueron de $49 \%$. Pacientes con comorbilidades (enfermedad cardiovascular, diabetes, enfermedad respiratoria crónica, hipertensión, cáncer) tienen altos rangos de fatalidad. ${ }^{39}$

EI SDRA es una entidad grave de elevada mortalidad. Fisiopatológicamente, en pediatría se presenta con edema pulmonar de origen no cardiogénico debido a una inflamación descontrolada ocasionada por SARS-CoV-2; induciendo liberación de citoquinas proinflamatorias y daño en el epitelio alveolar y el endotelio capilar; ocasiona un incremento en la permeabilidad de la barrera alveolo-capilar con fuga de fluidos del compartimento intravascular al extravascular pulmonar generando finalmente una acumulación de líquido rico en proteínas y células inflamatorias en los espacios alveolares. ${ }^{40}$ 
En los pacientes con infección por SARS-CoV-2 se ha evidenciado que la aparición de SDRA y enfermedad crítica se desarrolla con mayor frecuencia entre una y dos semanas después de la aparición de los primeros síntomas, por lo que consideramos que es el periodo en que los pacientes deben ser monitorizados más estrechamente. ${ }^{41}$

\section{Manifestaciones gastrointestinales}

Mientras que los pacientes con COVID-19 suelen presentar enfermedad respiratoria, otros han referido síntomas gastrointestinales que incluyen diarrea, vómito y dolor abdominal durante el curso de la enfermedad. ${ }^{42,43}$ Gao QY y colaboradores reportan que los más característicos son anorexia, náusea, vómito (1-3.6\%) y diarrea (2-10\%), siendo éste el síntoma más común. ${ }^{44}$ Sin embargo, en Hong Kong se evaluó la presencia de manifestaciones gastrointestinales y ARN en heces mediante un metaanálisis y revisión sistemática, que reportaron heterogeneidad significativa entre los estudios para anorexia, náusea, vómito y diarrea $\left(p<0.001 ; l^{2}\right.$ $=74.6-85.2 \%)$, mientras que la heterogeneidad fue menor para dolor abdominal $\left(p=0.008 ; I^{2}=\right.$ $57.0 \%) .{ }^{45}$ Algunos estudios sugieren que entre 3 y $10 \%$ de los pacientes que desarrollan infección pulmonar por SARS-CoV-2 presentaron inicialmente síntomas digestivos aislados y leves tales como anorexia, diarrea, náuseas, vómito y dolor abdominal, ${ }^{46}$ precediendo a síntomas respiratorios como fiebre, tos seca y disnea. ${ }^{37,47-49}$ Los resultados mostraron que los pacientes presentan vómito en $1.7 \%$ seguido de dolor abdominal en $11.9 \%$ y diarrea en $22 \%$, siendo este síntoma el más frecuente y se documentó que en estos pacientes se detectó mayor carga viral en muestras fecales.

Se piensa que una vez que el virus entra en la célula, el ARN y las proteínas específicas del virus se sintetizan en el citoplasma de ésta para ensamblar nuevos viriones, los cuales pueden liberarse al tracto gastrointestinal, ${ }^{50}$ siendo una teoría que sugiere que SARS-CoV-2 puede infectar activamente y replicarse en el tracto digestivo causando un conjunto de manifestaciones gastrointestinales..$^{51}$ El receptor ACE 2 se expresa en tracto gastrointestinal, especialmente en el intestino delgado y colon. Estos datos han proporcionado información valiosa en la entrada mediada por el receptor en las células del huésped y facilitan la base para su posible ruta de transmisión a través de contenidos fecales. ${ }^{42,46,50,52}$ Algunos estudios han reportado que pacientes confirmados con COVID-19 eliminan el ARN y las proteínas de SARS-CoV-2 en las heces de manera temprana y esta eliminación persiste después de que los síntomas respiratorios disminuyen. En estudios realizados en pacientes pediátricos sanos se ha confirmado la presencia de este virus mediante RT-PCR en heces, que sugiere una ruta de transmisión fecal-oral, permaneciendo hasta por 30 días. .,45,53 $^{-10}$

Por otra parte, se ha propuesto que ACE 2 está involucrada en la absorción de aminoácidos que regulan la expresión de péptidos relacionados con la homeostasis del microbioma intestinal, lo que sugiere que la actividad del virus puede causar modificaciones intestinales que incrementen la susceptibilidad a colitis y diarrea. ${ }^{44}$ Los pacientes que presentan síntomas gastrointestinales tienen mayor riesgo de morbilidad y mortalidad que aquéllos que no los presentan; es por ello que es necesario investigar síntomas como diarrea para el diagnóstico temprano de COVID-19. ${ }^{45}$ De acuerdo con reportes recientes en China, se evidenció que $79 \%$ de los casos confirmados provenían de un caso asintomático, por lo que debemos insistir en las medidas de prevención en niños, ${ }^{54,55}$ no descartando que existe una posible vía de transmisión fecal-oral, ya que se ha documentado la presencia de ARN viral en heces de pacientes pediátricos sanos, puesto que la excreción del virus en heces suele ser hasta por 30 días. . $^{5,45}$

Además de los síntomas gastrointestinales, los pacientes con COVID-19 pueden tener lesión hepática con elevación de enzimas hepáticas. Si bien el mecanismo de lesión hepática no se comprende completamente, la lesión puede deberse a los siguientes mecanismos: infección viral directa de los hepatocitos, lesión relacionada con la respuesta inmunitaria exagerada o hepatotoxicidad farmacológica.

La mayoría de las lesiones hepáticas son leves y transitorias, aunque puede producirse daño hepático grave. Se ha reportado que la proporción de lesión hepática es mayor en pacientes con COVID-19 grave ${ }^{42,56,57}$ Está bien documentado que en la infección por SARS hasta $60 \%$ de los pacientes presentaron daño hepático, sin olvidar que tuvieron tratamientos con fármacos potencialmente hepatotóxicos. ${ }^{46,56}$ Datos obtenidos mediante secuenciación de ARN de SARS-CoV-2 demostraron un aumento significativo en la expresión de ACE 2 en colangiocitos en lugar de los hepatocitos, lo que sugiere que este virus puede provocar lesiones directas en los conductos biliares intrahepáticos. ${ }^{58}$ 
Rev Latin Infect Pediatr 2020; 33 (s1): s10-s32

\section{Manifestaciones renales}

En pacientes con infecciones por SARS y MERSCoV se han descrito manifestaciones renales, siendo pocos los casos pediátricos reportados. En población adulta se ha encontrado entre 5 y $15 \%$ de afectación renal, siendo el hallazgo más característico la IRA. Actualmente se estima una incidencia de insuficiencia renal entre 3 y $9 \%$ en pacientes con infección por COVID-19; sin embargo, existen otras alteraciones a nivel renal como albuminuria, proteinuria y elevación de los azoados. Se ha reportado que los pacientes graves con falla renal, tienden a tener un pronóstico más sombrío, y en la mayoría de las ocasiones asociado con mortalidad hospitalaria. ${ }^{59}$

Se desconoce el mecanismo por el cual el SARSCoV-2 afecta las células renales, y son varios los mecanismos propuestos: ${ }^{60-62}$

1. Sepsis: debido a la presencia de citocinas por la respuesta inflamatoria sistémica secundaria.

2. Lesión celular directa inducida por el virus.

3. Expresión viral en receptores específicos Se ha obtenido incluso ARN viral en muestras de orina $y$ tejido renal. ${ }^{63}$ Debido a que el riñón cuenta con ACE 2 altamente expresada en el borde en cepillo de las células tubulares proximales y en menor medida en podocitos, se sugiere que el SARSCoV-2 puede tener tropismo hacia este órgano. ${ }^{64}$

Los posibles mecanismos de lesión del SARSCoV-2 a nivel renal incluyen infección directa a través del torrente sanguíneo debido a la alta expresión de ACE 2 así como a la tormenta de citoquinas relacionadas con la sepsis. ${ }^{65}$

Cheng y colaboradores ${ }^{59}$ informaron en una serie de 710 pacientes adultos hospitalizados con COVID19 que $26.7 \%$ presentó hematuria al ingreso, $44 \%$ desarrolló proteinuria y hematuria con niveles de creatinina sérica elevada y nitrógeno ureico elevado en $15.5 \%$ y $14.1 \%$, respectivamente. Durante el periodo de estudio, $3.2 \%$ de los pacientes presentaron insuficiencia renal aguda, falleciendo $12.3 \%$. Estos datos son obtenidos de estudios realizados en adultos, en población pediátrica aún no hay información al respecto. Sin embargo, se debe vigilar la función renal y los signos de daño renal principalmente hematuria y proteinuria de forma temprana.

Tampoco existen estudios completos que nos indiquen la influencia viral en las manifestaciones clínicas asociadas a falla renal, más bien, en los casos reportados, los pacientes estudiados contaban con IRC, lo cual explica el aumento del riesgo de morbimortalidad, considerando esta patología como un proceso inflamatorio crónico y estableciendo la enfermedad renal crónica como un factor de riesgo de desarrollar COVID-19 grave. ${ }^{66}$

Aun así, se reporta un incremento de la creatina en $5 \%$ de la población respecto a la basal previa normal, lo que traduce afectación a nivel renal de forma aguda que pudiera estar también implicada como factor asociado con deterioro sistémico. ${ }^{67}$

Se han estudiado pacientes con falla renal crónica, en los cuales se declaró el fallecimiento por causas no asociadas con la falla misma, sino más bien por un conjunto de manifestaciones cardiovasculares. Incluso, se han comparado pacientes con IRC en terapia de sustitución por hemodiálisis e infección por COVID-19 con pacientes sin afectación renal, y se concluyó que presentaban menor linfopenia, niveles séricos más bajos de citoquinas inflamatorias y enfermedad clínica más leve. ${ }^{63}$

Dentro de las manifestaciones renales descritas se encuentran las siguientes:

Al ingreso hospitalario se documentaron manifestaciones como proteinuria, hematuria, elevación de creatinina sérica, nitrógeno ureico elevado, y disminución de la filtración glomerular a $60 \mathrm{~mL} / \mathrm{min} / 1.73$ $\mathrm{m}^{2}$, siendo esta última un predictor de complicación y fallecimiento. ${ }^{68}$

Los indicadores de disfunción renal en pacientes con COVID-19 a nivel bioquímico siguen las pautas para el diagnóstico de insuficiencia renal en cualquier individuo. A su ingreso se sugiere contar con niveles de nitrógeno ureico en sangre y creatinina sérica. Otros parámetros a monitorizar en pacientes con afectación renal son: ácido úrico, creatinincinasa, y lactato deshidrogenasa, ya que se ha demostrado su aumento en pacientes renales con COVID-19. En el examen de orina se buscan datos sugestivos de proteinuria y hematuria. Su seguimiento y repetición deberá basarse en la evolución clínica y otras comorbilidades del paciente. ${ }^{69}$

Estudios de imagen por tomografía computarizada muestran alteraciones del tamaño y densidad de los riñones. Esto demuestra que la inflamación y el edema en parénquima renal pueden ocurrir en pacientes con COVID-19 previamente sanos. ${ }^{69}$ 
En el caso de pacientes con IRA con COVID-19 generalmente se ha documentado en estadios severos; los criterios para inicio de terapia de sustitución renal son los mismos que para pacientes sin la infección (control de volemia, depuración de tóxicos, corrección electrolítica, entre otros). No obstante, los pacientes que progresan en gravedad, se encuentran con otras alteraciones que en conjunto integran datos de falla orgánica múltiple; en estos casos las terapias extracorpóreas como la hemofiltración o la hemoperfusión ofrecen una nueva posibilidad de soporte a diferentes órganos. Usando circuitos y dispositivos extracorpóreos específicos, el corazón, pulmones, riñones y el hígado pueden ser reemplazados parcialmente o al menos sostenidos durante la fase grave del síndrome de falla orgánica. Las terapias de reemplazo renal continuo pueden ofrecer, en condiciones leves a graves de disfunción renal, un soporte significativo para el control de solutos y fluidos. ${ }^{70}$

No existe un tratamiento documentado para la infección por COVID-19. Se aconseja a los profesionales de salud que consulten las fichas técnicas de los medicamentos que estén autorizados en lo relativo a las recomendaciones de dosis, advertencias y precauciones, posibles reacciones adversas e interacciones. En su mayor parte la posología que se está utilizando en pacientes con SARS-CoV-2 es la misma que la recomendada en las indicaciones autorizadas para esos medicamentos. ${ }^{71}$

La Sociedad Internacional de Nefrología ha lanzado una serie de recomendaciones y sugerencias en la atención del paciente con enfermedad renal e infección por COVID-19, fijando como postura que no hay evidencia de que la infección por COVID-19 afecte negativamente a los riñones en aquellos pacientes con infección leve a moderada. Los pacientes más graves tienden a presentar proteinuria, hematuria y disminución en la tasa de filtrado glomerular, de ahí la importancia de su vigilancia y seguimiento. Por el momento no hay estudios suficientes que avalen los efectos a largo plazo a nivel renal de los pacientes recuperados de COVID-19..$^{72,73}$

Entre las recomendaciones para el manejo del paciente renal durante la pandemia de COVID-19 se enumeran las siguientes, con base en la experiencia de países con casos reportados de pacientes con tratamiento sustitutivo con diálisis peritoneal (ambulatoria y domiciliaria) así como pacientes con

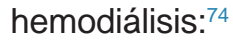

1. Continuar medidas de higiene adecuadas (aislamiento social, permanencia en el hogar, lavado de manos, evitar tocarse la cara, limitar el contacto con otras personas, principalmente si éstas tienen síntomas respiratorios).

2. No suspender tratamiento de sustitución renal.

3. En caso de encontrarse enfermo, comunicarse a su centro de diálisis y manifestar sus dudas, ellos le indicarán si es necesario acudir previamente a un hospital destinado a la atención de COVID-19 y descartar la infección.

4. Siempre se deberá informar al personal de diálisis sobre fiebre y síntomas respiratorios antes de acudir a su próxima cita programada.

5. En su centro de diálisis: el paciente debe continuar con medidas de distanciamiento y limpieza de manos, no se recomienda el uso de mascarilla de protección, a menos que el paciente manifieste alguna sintomatología respiratoria y previo a ello deberá informarlo para tomar las medidas pertinentes para su atención antes de su llegada.

6. Cuando sea paciente de hemodiálisis: lavarse las manos y el área de la fistula antes de comenzar la diálisis y desinfectar adecuadamente áreas de punción.

Si el paciente con tratamiento con diálisis tuvo contacto con un caso sospechoso o confirmado de COVID-19, se deben realizar las siguientes recomendaciones:

1. Comunicar al centro de diálisis para informar cómo sucedió el contacto y el personal pueda brindarle ciertas indicaciones para su atención.

2. En caso de ausencia de manifestaciones de enfermedad, usar mascarilla quirúrgica a su llegada al centro de diálisis, y durante toda su estancia, incluyendo realización de procedimientos.

3. Continuar con medidas de higiene y de permanencia en el hogar. Informe ante cualquier dato de alarma, y ante la necesidad de urgencia acuda al hospital de referencia.

En el caso de pacientes con terapia de sustitución renal domiciliaria se deberá brindar atención telefónica o vía electrónica para resolución de dudas, complementar con visitas domiciliarias de atención médica según se considere.

La Sociedad Americana de Trasplantes considera que no hay suficientes reportes de casos asociados a mayor predisposición de infección por COVID-19 
Rev Latin Infect Pediatr 2020; 33 (s1): s10-s32

en pacientes receptores de trasplante renal con respecto a la población en general; sin embargo, se considera que el tratamiento inmunosupresor y el contacto directo con familiares que no mantengan las medidas adecuadas de higiene, pueden ser clave en el desarrollo de la infección del paciente. Entre sus recomendaciones sobresalen: quedarse en casa, mantener distanciamiento social, evitar viajes a menos que sean estrictamente necesarios, sugiriéndose encarecidamente posponer viajes de familiares cuidadores en caso de conocer un caso sospechoso o confirmado, evitar contacto con el individuo, y en caso de presentar sintomatología informar a su coordinador de trasplantes. ${ }^{75}$

\section{Manifestaciones dermatológicas}

Como se ha evidenciado, el SARS-CoV-2 no sólo causa daño a nivel pulmonar y con la experiencia que han tenido otros países, cada día surgen datos que demuestran daños a varios órganos, dentro de éstos, la piel.

No existe suficiente información sobre las manifestaciones dermatológicas de COVID-19, sobre todo en pacientes pediátricos; sin embargo, es importante mencionar que se encuentran en fase de investigación. La bibliografía consultada corresponde en su mayoría a población adulta; sin embargo, debemos conocer cómo afecta el COVID-19 a la piel para realizar un adecuado diagnóstico, manejo y prevención de la propagación de la enfermedad.

En Wuhan, Zheng Y y colaboradores señalan que algunas dermatosis infecciosas cursan con fiebre, por lo que habría que determinar si son causadas por COVID-19 o se trata de una enfermedad dermatológica independiente. En estos pacientes, los signos y síntomas respiratorios, la historia epidemiológica y los estudios de laboratorio (ej., RT-PCR para COVID19) son importantes para establecer el diagnóstico; sin embargo, la falta de un tratamiento específico para la infección por SARS-CoV-2 promueve que las personas reciban antibióticos $u$ otros fármacos que puedan ser la causa primaria de una urticaria, vasculitis $u$ otro tipo de lesiones cutáneas en las que hay que considerar la posibilidad de reacciones alérgicas causadas por fármacos; adicionalmente, la tensión emocional que viven estos pacientes puede agravar la enfermedad dermatológica. ${ }^{76}$

Guan W y su equipo reportaron que $2 \%$ de un total de 1,099 pacientes, presentó erupciones cutáneas; sin embargo, no hacen mención de las caracterís- ticas de dichas erupciones. ${ }^{3}$ En Italia, un grupo de dermatólogos detectaron síntomas cutáneos en 88 pacientes, comprobando que 18 de ellos (20.4\%) desarrollaron manifestaciones cutáneas que iban desde un exantema eritematoso (14 pacientes), urticaria generalizada (tres pacientes) y vesículas tipo varicela (un paciente), afectando mayormente la zona del tronco, asociada con prurito leve y sin correlación con la gravedad de la enfermedad, con resolución de estas lesiones en pocos días. ${ }^{77}$

Existen algunos reportes de casos que se describen a continuación:

En Tailandia, un paciente fue diagnosticado erróneamente con dengue por presentar erupción petequial asociada con disminución de plaquetas, se agregó sintomatología respiratoria, por lo que se realizó RT-PCR para SARS-CoV-2, lo que confirmó la infección, descartando otra patología viral. ${ }^{78}$

En Estados Unidos se reportó el caso de un paciente de 26 años de edad en contacto cercano con persona infectada por SARS-CoV-2, que inició sintomatología respiratoria y 13 días posteriores apareció una erupción malar eritematosa, ligera-
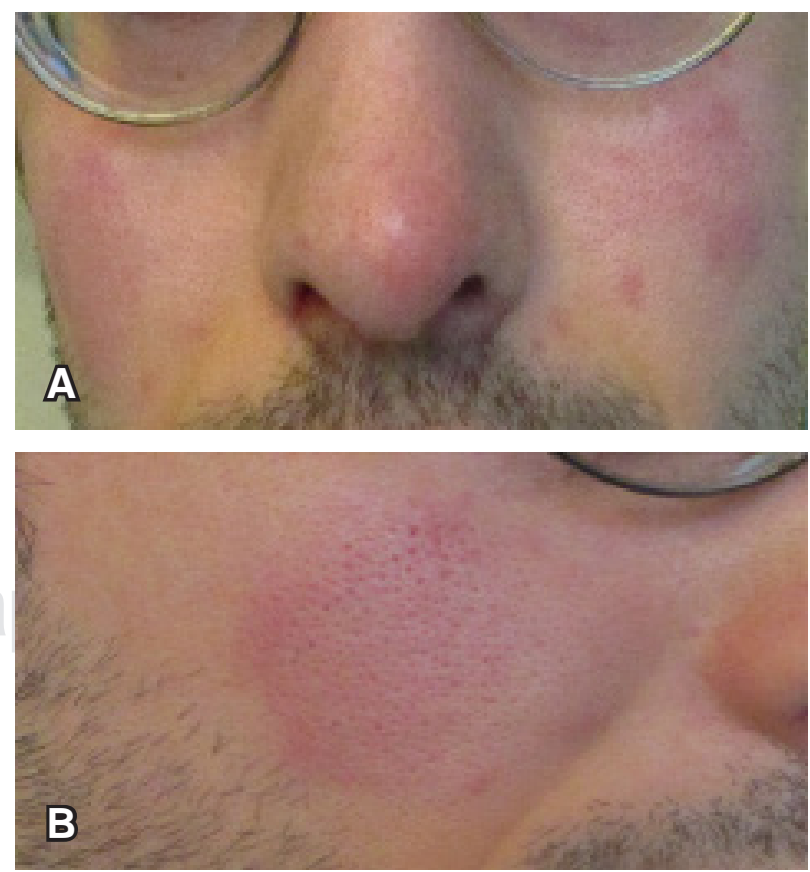

Figura 1: A y B. Erupción malar eritematosa, ligeramente edematosa sin cambios epidérmicos. Las imágenes se reproducen con autorización del Dr. Leonard J. Hoenig MD. ${ }^{79}$ 

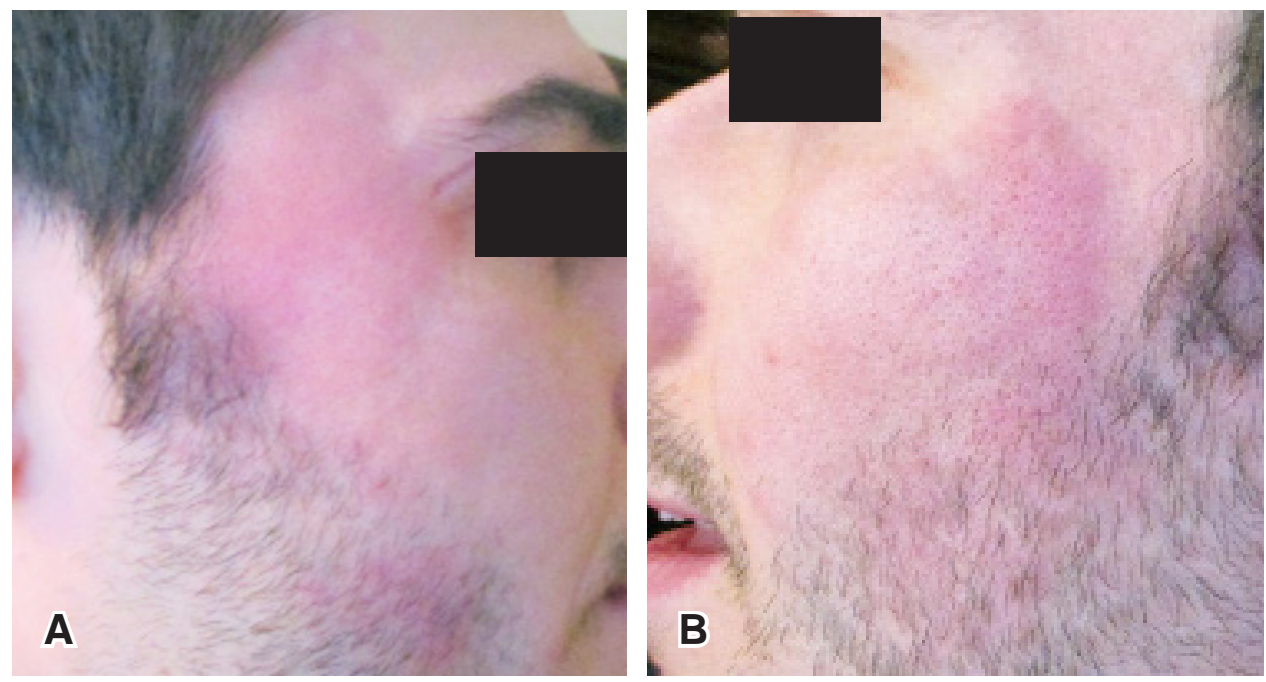

Figura 2:

\section{A y B. Erupción malar se} extiende hacia los temporales. Las imágenes se reproducen con autorización del Dr. Leonard J. Hoenig MD. ${ }^{79}$

mente edematosa (Figuras 1A y B), sin cambios epidérmicos. Para el día 15, la erupción malar se había extendido a los temporales (Figuras $2 A$ y $B$ ), junto con linfadenopatía sensible. Posteriormente, las áreas involucradas se volvieron rojas, hinchadas y sensibles. No se logró realizar RT-PCR para SARSCoV-2 a dicho paciente; sin embargo, por el contacto positivo y sintomatología respiratoria asociada se realizó un diagnóstico presuntivo de COVID-19. ${ }^{79}$

En Italia se reportó un paciente pediátrico de 13 años de edad que presentó repentinamente lesiones en los pies que eran redondeadas eritemato-violáceas de 5-15 $\mathrm{mm}$ de diámetro con límites borrosos en la superficie plantar del primer dedo del pie derecho y en la superficie dorsal del segundo dedo del pie derecho e izquierdo, sin asociación con otro síntoma o ingesta de fármacos, posteriormente inició con fiebre, mialgias, cefalea, prurito intenso y ardor en las lesiones del pie. Las lesiones persistieron después de siete días con la formación de costras negruzcas, presentando resolución espontánea; cabe resaltar que a este paciente no se realizó RT-PRC para SARS-CoV-2; sin embargo, las lesiones tenían características de otros casos reportados de SARS-CoV-2 positivo. ${ }^{80}$ Otro tipo de lesión reportada en pacientes positivos para SARS-CoV-2 es la aparición de un parche livedoide unilateral no pruriginoso transitorio en el muslo anterior derecho que se asemeja a livedo reticular (Figuras $3 A$ y $B$ ), uno de ellos asociado con hematuria macroscópica, resolviendo en 24 horas. ${ }^{81}$

En Wuhan, China se reportó acroisquemia en siete pacientes, asociada con alteración de la coagu- lación por aumento del dímero $\mathrm{D}$ de los productos de degradación de la fibrina y del fibrinógeno. Las lesiones fueron descritas como placas plantares, vesículas plantares, gangrena seca y hematomas en los dedos de manos y pies. Las placas plantares y la cianosis acral fueron las más comunes y se encontraban en todos los pacientes. La mediana del tiempo desde el inicio hasta la isquemia de las extremidades fue de 19 días. ${ }^{82}$

La Asociación Nacional de Dermatología y Venereología advirtió que se habían observado problemas cutáneos que van desde la aparición súbita de lesiones eritematosas persistentes, a veces dolorosas, hasta urticaria pasajera, ${ }^{83}$ por lo que se intentará categorizar la semiología cutánea y analizar su valor diagnóstico y pronóstico. ${ }^{84}$

Podemos sintetizar que las manifestaciones cutáneas asociadas a la infección viral hasta hoy son:

- Exantema/rash eritematoso (Figuras 1 y 2).

- Erupción urticariforme.

- Erupción vesiculosa.

- Lesiones acroisquémicas.

- Otras lesiones: livedo reticular en muslos, púrpura petequial folicular (Figuras $3 A$ y $B$ ).

Con respecto al tratamiento de las manifestaciones cutáneas es fundamentalmente sintomático en el caso del exantema: erupción urticariforme o erupción vesiculosa, se pueden pautar antihistamínicos, emolientes, antisépticos y corticoides tópicos en caso de sintomatología importante. 
Rev Latin Infect Pediatr 2020; 33 (s1): s10-s32

En relación con las lesiones acroisquémicas, los pacientes reportados previamente recibieron tratamiento con HBPM (entre 3,500 y 5,000 U al día). Estas lesiones mejoraron de forma progresiva en aquellos pacientes que superaron la enfermedad. Hasta la fecha, no existe evidencia científica del significado de estas lesiones en pacientes leves o paucisintomáticos o de su tratamiento. Para estos pacientes se aconseja observación clínica de las lesiones, evitar el frío y si son muy sintomáticas se ha recomendado nitroglicerina tópica $0.2 \%$, diltiazem $2 \%$ en gel, trinitrato de glicerol $4 \mathrm{mg} / \mathrm{g}$, corticoides tópicos (controvertido) o emolientes con lanolina y glicerina.

\section{Manifestaciones hematológicas}

Las manifestaciones hematológicas más importantes en los pacientes con infección por SARS-CoV-2 son las alteraciones en la cascada de coagulación y la
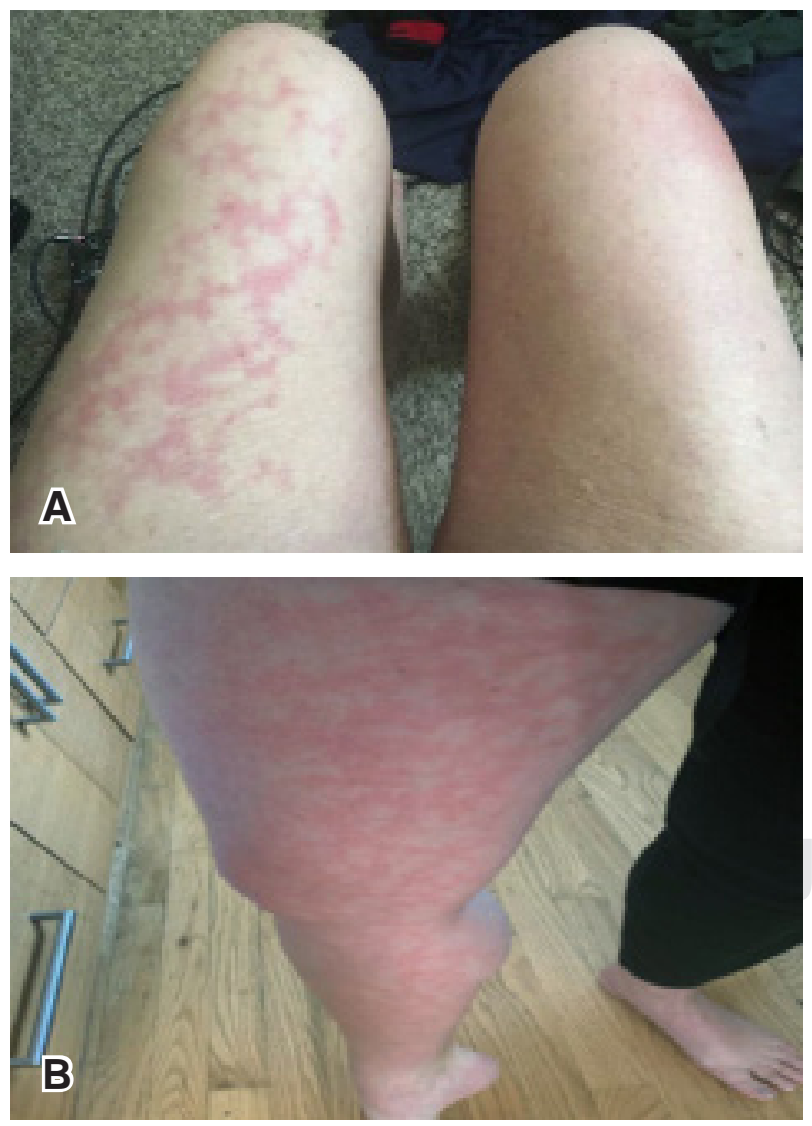

Figura 3: A y B. Parche livedoide unilateral no pruriginoso transitorio en el muslo anterior derecho que se asemeja a livedo reticular. Las imágenes se reproducen con autorización de la Dra. Iviensan F . Manalo. ${ }^{82}$ respuesta inflamatoria sistémica que desencadena. ${ }^{85}$ Una característica distintiva de COVID-19 grave es la coagulopatía: $71.4 \%$ de los pacientes que mueren presentan alteraciones en la coagulación cumpliendo criterios de la ISTH para CID. No se trata solamente de diátesis hemorrágica, existe una activación patológica de la trombina con múltiples episodios trombóticos que van desde isquemia periférica, tromboembolismo pulmonar hasta CID con niveles elevados de dímero $D$, altos niveles de fibrinógeno con niveles bajos de antitrombina, alargamiento moderado del tiempo de protrombina, tendencia a trombocitosis moderada, y congestión pulmonar con trombosis microvascular. ${ }^{86,87}$ Esta entidad, que acompaña a la respuesta macrofágica descontrolada, se ha denominado RITAC; el parámetro de laboratorio más apropiado para reconocer este estado trombofílico es el dímero D. ${ }^{19,20}$

Los pacientes críticamente enfermos con COVID19 desarrollan manifestaciones típicas de choque con acidosis metabólica grave indicando disfunción en la microcirculación, disfunción hepática y renal además del daño pulmonar. ${ }^{88}$ Dicho daño endotelial ocasiona la exposición de fibras de colágeno, llevando a un estado protrombótico que activa la cascada de coagulación, altera la reactividad de las plaquetas y genera vasoconstricción. Asimismo, ocurre activación del endotelio que aumenta su permeabilidad y la interacción con leucocitos, dando lugar a la diapédesis, quimiotaxis y producción de citocinas. El desarrollo de la CID se produce cuando esta interacción entre endotelio y leucocitos producen la liberación de citocinas, principalmente la IL-6 y la IL-8 (responsables de modular el inicio de la coagulación, ya que incrementan la expresión de moléculas de adhesión plaquetaria, leucocitos y células endoteliales) y de la IL-1 y el factor de necrosis tumoral $\alpha$ (TNF- $\alpha$ ) que inducen la atracción de los leucocitos al factor tisular, lo que da inicio a la cascada de coagulación. . $^{89,90}$

La evidencia de alteraciones en los parámetros de la coagulación se observó desde los reportes iniciales en Wuhan, ${ }^{91}$ con $6 \%$ de los pacientes con TTPa prolongado, $5 \%$ TP prolongado, $26 \%$ DD elevado, y trombocitopenia en $12 \%$ así como elevación de los biomarcadores de inflamación con VSG, PCR e IL-6 incrementadas. El tiempo promedio para el desarrollo de CID posterior a la admisión fue de cuatro días (de uno a 12 días).

Los factores asociados con mortalidad incluyen la elevación del $\mathrm{DD}>$ de $1,000 \mathrm{ng} / \mathrm{mL}$, prolongación del TP, elevación de IL-6 y troponina así 
como la existencia de comorbilidad incluyendo edad mayor de 60, diabetes, hipertensión y enfermedad coronaria. La presencia de un DD mayor de $1,000 \mathrm{ng} / \mathrm{mL}$ al ingreso se ha asociado con incremento en la mortalidad con un OR de 18.43 (2.64-128.55, p = 0.003). Se observó una reducción de $20 \%$ en la mortalidad en pacientes con un DD mayor de $3,000 \mathrm{ng} / \mathrm{mL}$ que fueron tratados con dosis profilácticas de heparina (32.8 vs. $52.4 \%, p=0.017) \cdot{ }^{91}$

EI RITAC se presenta principalmente en pacientes jóvenes, sin comorbilidad que se agravan rápidamente y que presentan síntomas relacionados con un SAM, con un desenlace fatal por una respuesta inmunitaria exagerada..$^{92}$ Los pacientes con SAM con SDRA grave sin otras comorbilidades asociadas se asocian con mayor mortalidad. ${ }^{93}$ El parámetro de laboratorio más apropiado para reconocer esta respuesta inmunitaria exagerada es una ferritina elevada. Es problemático reconocer el SAM/LHHs con inflamación pulmonar grave debido a que el proceso inflamatorio puede ser secundario al proceso neumónico con SDRA, y dado que el SAM es atípico, sin presencia de datos extrapulmonares, hace difícil su diferenciación, y en algunos casos puede haber SDRA sin SAM sobreagregada. Aunque la inflamación es más pulmonar que multiorgánica, la participación de IL-6 en el SAM asociado a COVID-19 se establece por los cambios bioquímicos incluyendo la ferritina, habiendo reportes preliminares de la eficacia del tratamiento con anticuerpos monoclonales antiIL-6R. ${ }^{94}$

La otra manifestación de los pacientes con RITAC es la trombosis, para reconocer este estado trombofílico usamos los niveles de DD elevado; en estos pacientes se presenta una activación patológica de la trombina, que provoca múltiples episodios trombóticos como isquemia periférica, CID, trombosis venosa profunda y tromboembolia pulmonar. ${ }^{91,95}$ Se ha reportado la presencia de anticuerpos antifosfolípidos en pacientes con COVID-19 y trombosis; sin embargo, el papel etiopatogénico de estos anticuerpos en la trombosis es difícil de determinar, ya que los anticuerpos pueden ser transitorios relacionados al proceso infeccioso; y también es complicado diferenciar de la coagulopatía asociada con COVID-19 que ocasiona estos eventos trombóticos. ${ }^{96}$

El diagnóstico de RITAC se establece con los siguientes criterios: ${ }^{95}$
- Paciente con infección confirmada de COVID-19 con síntomas respiratorios que presente uno 0 más de los siguientes criterios:

1. Dímero $D>1,000 \mathrm{ng} / \mathrm{mL}$

2. Ferritina $>500 \mathrm{ng} / \mathrm{mL}$

3. Disnea de rápida progresión

4. Hipoxemia refractaria

5. Fenómenos trombóticos

6. Choque

Se ha utilizado tocilizumab, un anticuerpo monoclonal antirreceptor de IL-6 en los pacientes con RITAC. Los estudios realizados en China son alentadores con remisión de la fiebre al primer día de su administración y disminución de los requerimientos de oxígeno en $75 \%$ de los pacientes. ${ }^{94}$

Para el tratamiento de pacientes con RITAC se ha sugerido: metotrexate a $1 \mathrm{mg} / \mathrm{kg} \mathrm{IM}$ en días alternos + HBPM a dosis de 0.5 a $1 \mathrm{U} / \mathrm{kg}$ cada 24 horas.

La evidencia y recomendaciones actualmente disponibles son de pacientes adultos, no podemos recomendar el tratamiento rutinario profiláctico, sino que se debe individualizar con base en el riesgo de trombosis asociado con SARS-CoV-2 y en la presencia de otros factores de riesgo. Debemos recordar que los anticoagulantes utilizados y aprobados en pediatría se limitan a HBPM como la enoxaparina y dalteparina, la heparina no fraccionada; y el tratamiento ambulatorio puede continuarse con enoxaparina o antagonistas de la vitamina $\mathrm{K}^{97}$ como se muestra en el capítulo de tratamiento.

Debemos hacer mención de una serie de teorías que han surgido sobre la afección de la hemoglobina directamente por el virus, justificando de forma errónea las manifestaciones clínicas $y$ el tratamiento. Podemos concluir que estas hipótesis no tienen fundamento científico y que el daño pulmonar, la hiperferritinemia y la coagulopatía descritas en pacientes con COVID-19 son secundarias a la neumonía que presentan dichos pacientes, y evolucionan a SDRA y al proceso inflamatorio excesivo con liberación de citocinas que ocasionan alteraciones en la coagulación y el estado protrombótico que se presenta en pacientes con enfermedad grave. No hay ninguna evidencia de que el virus entre a los glóbulos rojos y que interactúe con la hemoglobina, tampoco de que la sobrecarga de hierro ocasione un daño pulmonar importante. 
Rev Latin Infect Pediatr 2020; 33 (s1): s10-s32

\section{Manifestaciones neurológicas}

Se desconoce la incidencia de las manifestaciones neurológicas por SARS-CoV-2, siendo identificadas en forma tardía o retrospectiva. La cefalea, mialgias, fatiga y somnolencia suelen confundirse con alteraciones del estado general, no detallando su presentación y evolución. En algunas series las manifestaciones neurológicas las integran en una sola categoría, mientras que en otras las subdividen en alteraciones del sistema nervioso central, periférico, y músculo-esquelético, lo cual explica la gran diversidad en las incidencias reportadas por diferentes autores.

Se han propuesto diversos mecanismos patogénicos para explicar las manifestaciones neurológicas de COVID-19: por invasión directa del SNC, por vía hematógena, por vía linfática, por diseminación transináptica retrógrada a través del bulbo olfatorio $o$ a través de mecanorreceptores y quimiorreceptores pulmonares que envían señales al tracto solitario, aunado a los mecanismos inflamatorios y a la hipoxia de los pacientes. ${ }^{98-100}$

El virus tiene una afinidad muy particular por las neuronas de la médula oblongada, donde se encuentran los centros que controlan la dinámica respiratoria. El virus infecta a la célula utilizando los receptores de la ACE 2 detectados en células gliales y neuronas, ${ }^{98}$ diseminándose a través del torrente sanguíneo y por la lámina cribosa etmoidal. Aunque los informes reportan que los niños generalmente parecen tener una infección leve, se han descrito casos con manifestaciones neurológicas como crisis focales no motoras, encefalitis, miositis inflamatoria o polineuropatía. ${ }^{101,102}$ En adultos, más de un tercio de los pacientes han referido manifestaciones de SNC como cefalea, mareos, somnolencia, anosmia y ageusia, incluso EVC como complicación de la tormenta de citosinas y otros como su primera manifestación clínica. ${ }^{103}$ Estudios de neuroimagen han demostrado eventos vasculares isquémicos, trombosis, lesiones desmielinizantes, edema cerebral, siendo escasas las autopsias realizadas en las cuales han identificado edema cerebral, degeneración de la microglia y neuronal. ${ }^{104}$

La cefalea es una de las manifestaciones más frecuentes en los pacientes; sin embargo, al integrarla dentro de las manifestaciones neurológicas, sólo la reportan entre $6-23 \%$ sin características específicas, puede estar presente en cuadros clínicos leves o ser parte de las manifestaciones por neuroinfección. ${ }^{101,103,105}$
La enfermedad vascular cerebral se presenta en $2-3 \%$ de los pacientes críticos de mediana edad y ancianos con factores de riesgo asociados como hipertensión arterial, hiperlipidemia, diabetes mellitus o antecedente de enfermedad vascular cerebral. ${ }^{103,106,107}$

Se han reportado en pacientes pediátricos cuadros de encefalitis asociados a convulsiones farmacorresistentes, con evidencia de actividad delta frontal intermitente ocasionada por actividad citotóxica viral o por proceso inflamatorio autoinmune. En adultos existen reportes de casos con encefalitis en los que se realiza el diagnóstico confirmatorio en LCR a través de RT-PCR. ${ }^{108,109}$ Existe el reporte de un paciente con encefalopatía necrotizante aguda hemorrágica (también conocida como encefalitis fatal debido al mal pronóstico) que presentó deterioro súbito del alerta, cuya resonancia magnética mostró lesiones hemorrágicas en ambos tálamos, en la ínsula y la región medial de los lóbulos temporales. ${ }^{110}$ Esta encefalopatía necrosante hemorrágica aguda se ha reportado en pacientes inmunocomprometidos, con alteración del estado de alerta por disrupción parcial o total de la conciencia no atribuida a la condición pulmonar ni sistémica, además de otras manifestaciones como cefalea, mareo, accidentes cerebrovasculares, hemorragia cerebral, ataxia y epilepsia. Se recomienda modificar el soporte nutricional, evitando la sarcopenia, aumento del aporte de proteínas y suplementación con vitamina $\mathrm{C}$ y $\mathrm{D}$; el tratamiento comprende inmunoglobulina intravenosa y altas dosis de esteroides. ${ }^{111}$

La ageusia y/o anosmia se pueden encontrar en $5-88 \%$ de los casos, pueden ocurrir antes de las manifestaciones pulmonares y suelen ser transitorias con duración máxima de 21 días. ${ }^{106,112,113}$ Otras series reportan de 5.1 a $19.4 \%$ de los pacientes oligosintomáticos y puede ser el único síntoma presente así como alteraciones visuales, neuralgia y daño al músculo esquelético definido por dolor muscular y CPK > $200 \mathrm{U} / \mathrm{L}^{13}$

Los cuadros de miositis son reportados hasta en $27 \%$ de pacientes, con origen viral o autoinmune, de 13 a 19\% cursan con elevación sérica de CPK por arriba de $200 \mathrm{U} / \mathrm{L}$, siendo raros los casos que presentan rabdomiólisis. ${ }^{114}$

Se ha descrito un caso del síndrome de Guillain Barré con debilidad motora, polineuropatía desmielizante y disociación albúmino-citológica, en el cual existe controversia en cuanto a si fue secundario a la infección por SARS-CoV-2 o si fue coincidente. ${ }^{115}$ 
La mielitis aguda postinfecciosa es una complicación del SNC caracterizada por parálisis flácida, incontinencia urinaria y fecal. Se ha descrito en menor proporción que puede presentar falla ventilatoria aguda de origen central, edema cerebral e hipertensión intracraneana. ${ }^{16}$

\section{Manifestaciones cardiovasculares}

El sistema cardiovascular es el segundo órgano más afectado en la infección por SARS-CoV-2 debido a la presencia de receptores ACE 2 en el tejido miocárdico y en los vasos arteriales y venosos. ${ }^{116}$ Las complicaciones cardiovasculares que se han reportado son el daño al miocardio con o sin isquemia, arritmias, falla cardiaca, choque cardiogénico y miocarditis, ${ }^{116,117}$ aunque existen pocos estudios en población pediátrica.

Tavazzi y colaboradores reportaron el primer caso con diagnóstico histopatológico de miocarditis con identificación del SARS-CoV-2 en el tejido, ${ }^{118}$ y otros estudios histopatológicos han reportado edema e infiltrado inflamatorio tanto en el tejido miocárdico como vascular. ${ }^{104,118-120}$

Además de los síndromes coronarios agudos clásicos y otras afecciones como la miocarditis, la miocardiopatía de Takotsubo y las arritmias se han propuesto otros mecanismos de lesión cardiaca aguda debido a COVID-19 como la lesión miocárdica inducida por hipoxia, daño microvascular cardiaco debido a defectos de perfusión, hiperpermeabilidad de los vasos o angiospasmo, además del SRIS que incluye tormenta de citoquinas, inmunocitos desregulados e inflamación no controlada. ${ }^{121}$

La miocarditis aguda es frecuente en pacientes con COVID-19, evidencia niveles excesivamente elevados de IL- 6 en los pacientes que la desarrollan; esta tormenta de citocinas puede producir miocarditis fulminante con una mortalidad entre $40-70 \%$, principalmente en pacientes con falla multiorgánica. Se debe prestar más atención a pacientes con niveles extremadamente elevados de troponina I y arritmias de nueva aparición e iniciar de manera precoz tratamiento inmunomodulador (esteroides, inmunoglobulina, inhibidores de neuroaminidasa). ${ }^{123}$ El grado de daño miocárdico definido como aumento de troponinas por arriba de la percentil 99 se asocia a mayor hospitalización en la UCl y mortalidad en pacientes adultos. ${ }^{116,117}$

Las infecciones virales se asocian con disfunción metabólica, inflamación del miocardio y activación del sistema nervioso simpático que predispone a la arritmia cardiaca, incluyendo más frecuentemente, la fibrilación auricular, bloqueo atrioventricular, taquicardia ventricular y fibrilación ventricular. ${ }^{123}$

Se ha demostrado que la comorbilidad cardiovascular se asocia con COVID-19 más grave, incluso al igual que la ventilación mecánica y el ingreso en la UCI. Asimismo, la infección por SARS-CoV-2 puede aumentar la gravedad de las afecciones cardiacas subyacentes como la insuficiencia cardiaca congestiva y la cardiopatía isquémica. ${ }^{118}$

En pacientes sintomáticos con troponina alta y BNP alto, el diagnóstico de insuficiencia cardiaca es probable y debe establecerse con un ecocardiograma. En el caso de BNP/NT-proBNP bajo, la probabilidad de disfunción miocárdica relacionada con la lesión miocárdica es muy baja y la ecocardiografía no debe realizarse sistemáticamente. En este contexto de COVID-19 con troponina alta, los pacientes que presentan choque, signos de insuficiencia cardiaca aguda, sospecha de disfunción ventricular derecha, inestabilidad hemodinámica sin explicación clara y soplo cardiaco, la ecocardiografía también está indicada. Es claramente útil para la evaluación de la función miocárdica, la detección de anormalidades de la contracción de la pared regional y la enfermedad valvular aguda. ${ }^{121}$

En recién nacidos y niños, la cirugía cardiaca previa está relacionada con riesgo de forma más grave de la enfermedad, ingreso a la $\mathrm{UCl}$ y necesidad de intubación y ventilación mecánica: ${ }^{15}$ y se han recopilado datos sobre un aumento de troponina I como marcador de lesión miocárdica en niños. ${ }^{124}$ Los niños con COVID-19 comparten problemas de ritmo; sin embargo, se han reportado arritmias menos dañinas que en los adultos como taquicardia supraventricular, bloqueos auriculoventriculares de primer grado y bloqueo incompleto de rama derecha. ${ }^{15}$

Los diferentes grupos de especialistas en ecocardiografía pediátrica establecen que en pacientes con sospecha o confirmación de COVID-19, las imágenes cardiacas deben realizarse al lado de la cama del paciente y se determinará si éste es candidato a realizarlo, cuando el estudio mejore sustancialmente su manejo o salve vidas, ya que el riesgo de propagación de la infección involucra personal, equipo e instalaciones, considerando que cuanto más tiempo se requiere para la obtención de imágenes, mayor es el riesgo de infección. A este respecto, se sugiere un estudio ecocardiográfico enfocado a la función cardiaca y a descartar la presencia de tamponade cardiaco para acortar 
Rev Latin Infect Pediatr 2020; 33 (s1): s10-s32

el tiempo de exposición y no como un estudio de seguimiento..$^{15,125}$

Una de las principales complicaciones en los pacientes pediátricos con infección por COVID-19 en una etapa tardía es el PIMS, se considera un síndrome nuevo que está temporalmente relacionado con la exposición previa al SARS-CoV-2. ${ }^{126-128}$

Los pacientes con PIMS presentan elevación en marcadores inflamatorios, además de elevación de troponinas y NT-proBNP al igual que disfunción sistólica ventricular izquierda. ${ }^{127} \mathrm{La}$ afectación miocárdica con insuficiencia cardiaca aguda probablemente se deba al aturdimiento miocárdico o al edema más que al daño inflamatorio del miocardio. ${ }^{126}$

Se ha observado que estos pacientes manifiestan características que se superponen con el síndrome de choque tóxico y la enfermedad de Kawasaki atípica junto con la inflamación cardiaca. El síndrome de choque de la enfermedad de Kawasaki se manifiesta principalmente con presión arterial sistólica baja o signos clínicos de mala perfusión. La disfunción sistólica del ventrículo izquierdo se observa sólo en un tercio de los pacientes, pero la disfunción diastólica de larga duración es un hallazgo destacado en este síndrome. Por lo tanto, el PIMS puede compartir algunos aspectos de la fisiología del síndrome de choque por Kawasaki, pero la disfunción sistólica del ventrículo izquierdo es más frecuente ${ }^{126,129}$ y consideramos que los pacientes con sospecha diagnóstica de PIMS deben contar con una evaluación cardiovascular de inicio que incluya la clínica, electrocardiograma, enzimas cardiacas (troponinas y NT-proBNP) basales, que en caso de incrementar o tener deterioro hemodinámico con cambios electrocardiográficos se valorará la realización de un ecocardiograma tomando en cuenta que es un estudio complementario, no una herramienta para tomar decisiones terapéuticas.

Belhadjer y colaboradores ${ }^{126}$ reportaron un estudio de 35 pacientes que cumplían los criterios de inclusión con choque cardiogénico febril o disfunción ventricular izquierda y estado inflamatorio: la infección por SARS-CoV-2 se confirmó en 31/35 pacientes (88.5\%), la RT-PCR en hisopo nasofaríngeo fue positiva en 12 pacientes (34\%) y la RT-PCR fecal en dos pacientes (6\%); 30 de $35(86 \%)$ pacientes tuvieron análisis de anticuerpos positivos: 23 tenían IgA e lgG, tres tenían IgG, dos tenían IgG e lgM y dos sólo tenían IgA. Además, dos pacientes fueron negativos para la RT-PCR para SARS-CoV-2, pero tenían características típicas por TAC de neumonía por COVID-19, faltando resultados en cinco pacientes.

\section{CONCLUSIONES}

La infección por SARS-CoV-2 representa un reto clínico debido a la afección multiorgánica que puede presentarse. Si bien el sistema respiratorio es el más afectado y la principal causa de mortalidad, el resto de las complicaciones pueden empeorar el pronóstico y dejar secuelas posteriores, por lo que el manejo de pacientes con COVID-19 deberá ser con un enfoque multidisciplinario.

\section{REFERENCIAS}

1. Huang C, Wang Y, Li X, Ren L, Zhao J, Hu Y et al. Clinical features of patients infected with 2019 novel coronavirus in Wuhan, China. Lancet [Internet]. 2020; 395 (10223): 497506. Available from: https://www.thelancet.com/action/sho wPdf?pii=S0140-6736\%2820\%2930183-5

2. Ramanathan K, Antognini D, Combes A, Paden M, Zakhary $\mathrm{B}$, Ogino $\mathrm{M}$ et al. Clinical characteristics and diagnostic challenges of pediatric COVID-19: a systematic review and meta-analysis. J Formos Med Assoc. 2020; 19-21.

3. Guan W, Ni Z, Hu YYY, Liang W, Ou C, He J et al. Clinical characteristics of coronavirus disease 2019 in China. N Engl J Med [Internet]. 2020; 382 (18): 1708-1720. Available from: https://www.nejm.org/doi/pdf/10.1056/ nejmoa2002032

4. Liu W, Zhang Q, Chen J, Xiang R, Song H, Shu S. Detection of Covid-19 in children in early January 2020 in Wuhan, China. N Engl J Med. 2020; 382: 1370-1371.

5. Jiehao C, Jing X, Daojiong L, Lei X, Zhenghai Q, Yuehua Z et al. A case series of children with 2019 novel coronavirus infection: clinical and epidemiological features. Clin Infect Dis [Internet]. 2020; 71 (6): 1547-1551. Available from: https://watermark.silverchair.com/ciaa198.pdf?token=AQ ECAHi208BE49Ooan9kkhW_Ercy7Dm3ZL_9Cf3qfKAc48 5ysgAAAmswggJnBgkqhkiG9w0BBwagggJYMIICVAIBAD CCAk0GCSqGSIb3DQEHATAeBglghkgBZQMEAS4wEQ QM1i3M7PHkC6dAzL12AgEQgllCHtn40-AX0dBKm8bw1kHsLT7OPT9cbRqoEDGRGxEbQOEYp1

6. Wei M, Yuan J, Liu Y, Fu T, Yu X, Zhang ZJ. Novel coronavirus infection in hospitalized infants under 1 year of age in China. JAMA [Internet]. 2020; 323 (13): 1313-1314. Available from: https://scholar.google.com/ scholar_url?url=https://jamanetwork.com/journals/jama/ articlepdf/2761659/jama_wei_2020_Id_200011.pdf\&hl=es $\& s a=T \& o i=u c a s a \& c t=u f r \& e i=1$ hyjXtTqHdS5ygTUiqrACQ\& scisig=AAGBfm10yWRCsrPZldbfD9MqncsOooAlgA

7. Saavedra-Trujillo $\mathrm{CH}$. Consenso colombiano de atención, diagnóstico y manejo de infección por SARS-COV-2/ COVID-19 en establecimientos de atención de la salud. Recomendaciones basadas en el consenso de expertos e informadas en la evidencia. Asociación Colombiana de Infectología. Infectio [Internet]. 2020; 24 (3): 1-153. Disponible en: https://www.revistainfectio.org/index.php/ infectio/article/view/851/946

8. Tiago $\mathrm{H}$, de Souza JAN. Clinical manifestations of children with COVID-19: a systematic review Tiago H. de Souza. meRxiv [Internet]. 2020. Available from: https://www.medrxiv. org/content/10.1101/2020.04.01.20049833v2.full.pdf 
9. Guo YR, Cao QD, Hong ZS, Tan YY, Chen SD, Jin HJ et al. The origin, transmission and clinical therapies on coronavirus disease 2019 (COVID-19) outbreak - an update on the status. Mil Med Res [Internet]. 2020; 7 (1): 11. Available from: https://mmrjournal.biomedcentral.com/ track/pdf/10.1186/s40779-020-00240-0

10. Dong Y, Mo X, Hu Y, Qi X, Jiang F, Jiang Z. Epidemiology of COVID-19 Among children in China. Pediatrics [Internet]. 2020; 145: e20200702. Available from: https://pediatrics. aappublications.org/content/pediatrics/early/2020/03/16/ peds.2020-0702.1.full.pdf

11. Secretaría de Salud Federal. Aviso epidemiológico. Enfermedad COVID-19 por SARS-CoV-2 [Internet]. 2020. Disponible en: https://www.gob.mx/cms/uploads/ attachment/file/541794/AE_Enfermedad_COVID-19_ SARS-CoV-2_2020.03.17.pdf

12. Bagheri SHR, Asghari AM, Farhadi M, Shamshiri AR, Kabir A, Kamrava SK et al. Coincidence of COVID-19 epidemic and olfactory dysfunction outbreak. medRxiv [Internet]. 2020. Available from: https://www.medrxiv.org/content/10 .1101/2020.03.23.20041889v1.full.pdf

13. Mao L, Wang M, Chen S, He Q, Chang J, Hong C et al. Neurological manifestations of hospitalized patients with COVID-19 in Wuhan, China: a retrospective case series study. medRxiv [Internet]. 2020. Available from: https://www.medrxiv. org/content/10.1101/2020.02.22.20026500v1.full.pdf+html

14. World Health Organization. Global surveillance for human infection with coronavirus disease (COVID-19) [Internet]. Interim Guidance. 2020. pp. 27-29. Available from: https:// www.who.int/publications-detail/global-surveillance-forhuman-infection-with-novel-coronavirus-(2019-ncov)

15. Xia W, Shao J, Guo Y, Peng X, Li Z, Hu D. Clinical and CT features in pediatric patients with COVID-19 infection: different points from adults. Pediatr Pulmonol [Internet]. 2020; 55 (5): 1169-1174. Available from: https:// onlinelibrary.wiley.com/doi/epdf/10.1002/ppul.24718

16. Yoon SH, Lee KH, Kim JY, Lee YK, Ko H, Kim KH et al. Chest radiographic and ct findings of the 2019 novel coronavirus disease (Covid-19): analysis of nine patients treated in Korea. Korean J Radiol [Internet]. 2020; 21 (4): 498-504. Available from: https://www.ncbi.nlm.nih.gov/ pmc/articles/PMC7082662/pdf/kjr-21-494.pdf

17. Dirección General de Epidemiología. Lineamiento estandarizado para la vigilancia epidemiológica y por laboratorios de COVID-19 [Internet]. Secretaría de Salud Gobierno de México. 2020. pp. 1-58. Disponible en: https://www.gob.mx/cms/uploads/attachment/file/537944/ Lineamiento_COVID-19_2020.02.27.pdf

18. Calvo Rey M, García-López Hortelano J, Tomás Ramos F, Baquero Navarro M. Documento de manejo clínico del paciente pediátrico con infección por SARS-CoV-2. Extracto del Documento de Manejo Clínico del Ministerio de Sanidad Redactores pertenecientes a la Asociación Española de Pediatría (AEP): Sociedad Española de Infectología Pediátrica [Internet]. 2020. pp. 1-17. Disponible en: https://www.analesdepediatria.org/contenidos/pdf/ Recomendaciones pediatricas Covid1.pdf

19. World Health Organization (WHO). Clinical management of severe acute respiratory infection when novel coronavirus (nCoV) infection is suspected. 2020. Available from: https:// www.who.int/publications-detail/clinical-managementof-severe-acute-respiratory-infection-when-novelcoronavirus-(ncov)-infection-is-suspected
20. Weiss SL, Peters MJ, Alhazzani W, Agus MSD, Flori HR Inwald DP et al. Surviving sepsis campaign international guidelines for the management of septic shock and sepsisassociated organ dysfunction in children. Pediatr Crit Care Med. 2020; 21 (2): e52-e106.

21. Calvo C, García López-Hortelano M, De Carlos Vicente JC, Vázquez Martínez JL y Grupo de trabajo de la Asociación Española de Pediatría. Recomendaciones sobre el manejo clínico de la infección por el «nuevo coronavirus» SARS-CoV2. Grupo de trabajo de la Asociación Española de Pediatría (AEP). An Pediatr (Barc) [Internet]. 2020; 92 (4): 241.e1-241.e11. Disponible en: https://www. analesdepediatria.org/es-pdf-S169540332030076X

22. Fang $Y$, Han $Y$, Feng Z, Sun L, Ren X, Wang $H$ et al. A comparative-descriptive analysis of clinical characteristics in 2019-Coronavirus-infected children and adults. J Med Virol. 2020; 10.1002/jmv.25835.

23. Yang P, Liu P, Li D, Zhao D. Corona virus disease 2019, a growing threat to children? J Infect [Internet]. 2020; 80 (6): 671-693. Available from: https://www.ncbi.nlm.nih.gov/ pmc/articles/PMC7125808/pdf/main.pdf

24. Al-Tawfiq JA, Memish ZA. Diagnosis of SARS-CoV-2 infection based on CT scan vs RT-PCR: reflecting on experience from MERS-CoV. J Hosp Infect [Internet] 2020; 105 (2): 154-155. Available from: https://www. journalofhospitalinfection.com/action/showPdf?pii $=$ S0195-6701\%2820\%2930100-6

25. Brodin P. Why is COVID-19 so mild in children? Acta Paediatr. 2020; 109 (6): 1082-1083.

26. Yonker LM, Shen K, Kinane TB. Lessons unfolding from pediatric cases of COVID-19 disease caused by SARSCoV-2 infection. Pediatr Pulmonol [Internet]. 2020; 55: 1085-1086. Available from: https://onlinelibrary.wiley.com/ doi/pdf/10.1002/ppul.24748

27. Choi SH, Kim HW, Kang JM, Kim DH, Cho EY. Epidemiology and clinical features of coronavirus disease 2019 in children. Clin Exp Pediatr [Internet]. 2020; 63 (4): 125-132. Available from: https://www.e-cep.org/upload/pdf/ cep-2020-00535.pdf

28. Hagmann SHF. COVID-19 in children: More than meets the eye. Travel Med Infect Dis [Internet]. 2020; 34: 101649. Available from: https://reader.elsevier.com/reader/sd/pii/S1 477893920301174?token=02C6232597CD9CEBEE34B8 C157D80B678BDEA668612C0C634C2715A817AAD080 B09CB1491E1B9BEF99F72872F4A5E1A1

29. Zhu L, Wang J, Huang R, Liu L, Zhao H, Wu C. Clinical characteristics of a case series of children with coronavirus disease 2019. Pediatr Pulmonol. 2020; 55 (6): 1430-1432.

30. She J, Liu L, Liu W. COVID-19 epidemic: disease characteristics in children. J Med Virol [Internet]. 2020; 92 (7): 747-754. Available from: https://onlinelibrary.wiley. com/doi/pdf/10.1002/jmv.25807

31. Qiu H, Wu J, Hong L, Luo Y, Song Q, Chen D. Clinical and epidemiological features of 36 children with coronavirus disease 2019 (COVID-19) in Zhejiang, China: an observational cohort study. Lancet Infect Dis. 2020; 20 (6):C 689-696.

32. CDC COVID-19 Response Team. Coronavirus Disease 2019 in Children - United States, February 12-April 2, 2020. MMWR Morb Mortal Wkly Rep. 2020; 69 (14): 422-426.

33. Kolifarhood G, Aghaali M, Mozafar Saadati H et al Epidemiological and clinical aspects of COVID-19; a 
Rev Latin Infect Pediatr 2020; 33 (s1): s10-s32

narrative review. Arch Acad Emerg Med [Internet]. 2020; 8 (1): e41. Available from: https://www.ncbi.nlm.nih.gov/pmc/ articles/PMC7117787/pdf/aaem-8-e41.pdf

34. Lu X, Zhang L, Du H et al. SARS-CoV-2 infection in children. N Engl J Med [Internet]. 2020; 382 (17): 1663-1665. Available from: https://www.nejm.org/doi/ pdf/10.1056/NEJMc2005073

35. Lechien JR, Chiesa-Estomba CM, De Siati DR, Horoi M, Le Bon SD, Rodriguez $A$ et al. Olfactory and gustatory dysfunctions as a clinical presentation of mild-tomoderate forms of the coronavirus disease (COVID-19): a multicenter European study. Eur Arch Otorhinolaryngol [Internet]. 2020; 277 (8): 2251-2261. Available from: https://link.springer.com/content/pdf/10.1007/s00405020-05965-1.pdf

36. Cascella M, Rajnik M, Cuomo A, Dulebohn SC, Di Napoli R. Features, evaluation, and treatment of coronavirus (COVID-19). In: StatPearls [Internet]. Treasure Island (FL): StatPearls Publishing; 2020. Available from: https://www. ncbi.nlm.nih.gov/books/NBK554776/

37. Chen N, Zhou M, Dong X et al. Epidemiological and clinical characteristics of 99 cases of 2019 novel coronavirus pneumonia in Wuhan, China: a descriptive study. Lancet [Internet]. 2020; 395 (10223): 507-513. Available from: https://www.thelancet.com/action/showPdf?pii $=$ S0140-6736\% $2820 \% 2930211-7$

38. Li SR, Tang ZJ, Li ZH, Liu X. Searching therapeutic strategy of new coronavirus pneumonia from angiotensinconverting enzyme 2: the target of COVID-19 and SARSCoV. Eur J Clin Microbiol Infect Dis [Internet]. 2020; 39 (6): 1021-1026. Available from: https://www.unboundmedicine. com/medline/citation/32285293/Searching_therapeutic_ strategy_of_new_coronavirus_pneumonia_from _ angiotensin_converting_enzyme_2: _the_target_of_ COVID 19 and SARS CoV

39. Wang $\bar{Y}$, Wang $\bar{Y}$, Chen $Y$, Qin $Q$. Unique epidemiological and clinical features of the emerging 2019 novel coronavirus pneumonia (COVID-19) implicate special control measures. J Med Virol [Internet]. 2020; 92 (6): 568576. Available from: https://onlinelibrary.wiley.com/doi/ pdf/10.1002/jmv.25748

40. Rivero KN, Araneda KP, Astorga KE, Améstica KM, Cruces $P$. Síndrome de distrés respiratorio agudo en pediatría. Neumol Pediatr. 2016; 11 (4): 168-174.

41. Goh KJ, Choong MC, Cheong EH, Kalimuddin S, Duu Wen $\mathrm{S}$, Phua GC et al. Rapid progression to acute respiratory distress syndrome: review of current understanding of critical illness from COVID-19 infection. Ann Acad Med Singap. 2020; 49 (3): 108-118.

42. Wong SH, Lui RN, Sung JJ. Covid-19 and the digestive system. J Gastroenterol Hepatol [Internet]. 2020; 35 (5): 744-748. Available from: https://onlinelibrary.wiley.com/doi/ pdf/10.1111/jgh.15047

43. D'Amico F, Baumgart DC, Danese S, Peyrin-Biroulet L. Diarrhea during COVID-19 infection: pathogenesis, epidemiology, prevention, and management. Clin Gastroenterol Hepatol [Internet]. 2020; 18 (8): 1663-1672. Available from: https://www.cghjournal.org/article/S15423565(20)30481-X/pdf

44. Gao QY, Chen YX, Fang JY. 2019 Novel coronavirus infection and gastrointestinal tract. J Dig Dis [Internet]. 2020; 21 (3): 125-126. Available from: https://onlinelibrary. wiley.com/doi/pdf/10.1111/1751-2980.12851?casa_
token=QDEP-vw1IBIAAAAA:bYzUxaVnF52JhpWrXtT3Lriw5iwfcCD-RvVwnbmR594ugg83VEM3lyMVm x8Hbv0O3CEH2ruv-U79As

45. Gastrointestinal manifestations of SARS-CoV-2 infection and virus load in fecal samples from a Hong Kong cohort: systematic review and meta-analysis. Gastroenterology [Internet]. 2020; 159 (1): 81-95. Available from: https://doi. org/10.1053/j.gastro.2020.03.065

46. Lee IC, Huo TI, Huang YH. Gastrointestinal and liver manifestations in patients with COVID-19. J Chin Med Assoc [Internet]. 2020; 83 (6): 521-523. Available from: https://www.ncbi.nlm.nih.gov/pmc/articles/ PMC7176263/pdf/ca9-publish-ahead-of-print-10.1097. jcma.0000000000000319.pdf

47. Xu XW, Wu XX, Jiang XG, Xu KJ, Ying LJ, Ma CL et al. Clinical findings in a group of patients infected with the 2019 novel coronavirus (SARS-Cov-2) outside of Wuhan, China: retrospective case series. BMJ. 2020; 368: $\mathrm{m} 606$.

48. Wang D, Hu B, Hu C, Zhu F, Liu X, Zhang J et al. Clinical characteristics of 138 hospitalized patients with 2019 novel coronavirus-infected pneumonia in Wuhan, China. JAMA. 2020; 323 (11): 1061-1069.

49. Riddle MS, Dupont HL, Connor BA. ACG clinical guideline: diagnosis, treatment, and prevention of acute diarrheal infections in adults. Am J Gastroenterol. 2016; 111 (5): 602-622.

50. Xiao F, Tang M, Zheng X, Liu Y, Li X, Shan H. Evidence for gastrointestinal infection of SARS-CoV-2. Gastroenterology [Internet]. 2020; 158 (6): 1831-1833.e3. Available from: https://www.gastrojournal.org/article/S00165085(20)30282-1/pdf?referrer=https\%3A\%2F\%2Fwww. ncbi.nlm.nih.gov\%2F

51. Carvalho A, Alqusairi R, Adams A, Paul M, Kothari N, Peters $S$ et al. SARS-CoV-2 gastrointestinal infection causing hemorrhagic colitis: implications for detection and transmission of COVID-19 disease. Am J Gastroenterol [Internet]. 2020; 115 (6): 942-946. Available from: https:// journals.Iww.com/ajg/Documents/COVID19_Carvalho_et_ al_AJG_Preproof.pdf

52. Li LY, Wu W, Chen S, Gu JW, Li XL, Song HJ et al. Digestive system involvement of novel coronavirus infection: Prevention and control infection from a gastroenterology perspective. J Dig Dis [Internet]. 2020; 21 (4): 199-204. Available from: onlinelibrary.wiley.com/doi/ pdf/10.1111/1751-2980.12862?casa_token=8CDzcyGwpe YAAAAA:TNgtBh4GDEhvILZpm8YD_2M9PxunschMsUR 781B6hsggyoWCDxHU-dtxSAsL402yl_C3i9U61Q9kx5I

53. Gu J, Han B, Wang J. COVID-19: gastrointestinal manifestations and potential fecal-oral transmission. Gastroenterology [Internet]. 2020; 158 (6): 1518-1519. Available from: https://www.gastrojournal.org/article/ S0016-5085(20)30281-X/pdf

54. van Doremalen N, Bushmaker T, Morris DH, Holbrook MG, Gamble A, Williamson BN et al. Aerosol and surface stability of SARS-CoV-2 as compared with SARS-CoV-1. N Engl J Med [Internet]. 2020; 382 (16): 1564-1567. Available from: https://www.nejm.org/doi/pdf/10.1056/ NEJMc2004973

55. Li R, Pei S, Chen B, Song Y, Zhang T, Yang W et al. Substantial undocumented infection facilitates the rapid dissemination of novel coronavirus (SARS-CoV-2). Science [Internet]. 2020; 368 (6490): 489-493. Available from: 
https://www.ncbi.nlm.nih.gov/pmc/articles/PMC7164387/ pdf/abb3221.pdf

56. Chau TN, Lee KC, Yao H, Tsang TY, Chow TC, Yeung YC et al. SARS-associated viral hepatitis caused by a novel coronavirus: report of three cases. Hepatology. 2004; 39 (2): 302-310.

57. Zhang Y, Zheng L, Liu L, Zhao M, Xiao J, Zhao Q. Liver impairment in COVID-19 patients: a retrospective analysis of 115 cases from a single centre in Wuhan city, China. Liver Int [Internet]. 2020; 40 (9): 2095-2103. Available from: https:// onlinelibrary.wiley.com/doi/pdf/10.1111/liv.14455?casa_ token=3IXSe_TZRCUAAAAA:oQPbgM4m4M6IkUd8aSjtUNu0KG25hbb_luey8sF4XGpHUCYcN7qei3QpA_ GLP5c2z0LePzSOJNh5j8

58. Chai $X$, Hu L, Zhang $Y$ et al. Specific ACE2 expression in cholangiocytes may cause liver damage after 2019-ncov infection. bioRxiv [Internet]. 2020. Available from: https:// www.biorxiv.org/content/10.1101/2020.02.03.931766v1. full.pdf

59. Cheng Y, Luo R, Wang K, Zhang M, Wang Z, Dong L et al. Kidney impairment is associated with in-hospital death of COVID-19 patients. Kidney Int [Internet]. 2020; 97: 829838. Available from: https://www.kidney-international.org/ article/S0085-2538(20)30255-6/pdf

60. Mou H, Raj VS, van Kuppeveld FJM, Rottier PJM, Haagmans BL, Bosch BJ. The receptor binding domain of the new middle east respiratory syndrome coronavirus maps to a 231-residue region in the spike protein that efficiently elicits neutralizing antibodies. J Virol. 2013; 87 (16): 9379-9383.

61. Vaduganathan M, Vardeny $\mathrm{O}$, Michel T, McMurray JJV, Pfeffer MA, Solomon SD. Renin-angiotensin-aldosterone system inhibitors in patients with Covid-19. N Engl J Med [Internet]. 2020; 382 (17): 1653-1659. Available from: https://www.ncbi.nlm.nih.gov/pmc/articles/PMC7121452/ pdf/NEJMsr2005760.pdf

62. Liu Z, Xiao X, Wei X, Li J, Yang J, Tan H et al. Composition and divergence of coronavirus spike proteins and host ACE2 receptors predict potential intermediate hosts of SARS-CoV-2. J Med Virol. 2020; 92 (6): 595-601.

63. Naicker S, Yang CW, Hwang SJ, Liu BC, Chen JH, Jha V. The novel coronavirus 2019 epidemic and kidneys. Kidney Int. 2020; 97 (5): 824-828.

64. Perico L, Benigni A, Remuzzi G. Should COVID-19 concern nephrologists? Why and to what extent? The emerging impasse of angiotensin blockade. Nephron. 2020; 144 (5): 213-221.

65. Larsen CP, Bourne TD, Wilson JD, Saqqa O, Sharshir MA. Collapsing glomerulopathy in a patient with COVID-19. Kidney Int Rep [Internet]. 2020; 5 (6): 935-939. Available from: https://www.ncbi.nlm.nih.gov/pmc/articles/ PMC7142700/

66. Henry BM, Lippi G. Chronic kidney disease is associated with severe coronavirus disease 2019 (COVID-19) infection. Int Urol Nephrol. 2020; 52 (6): 1193-1194.

67. Betjes MG. Immune cell dysfunction and inflammation in endstage renal disease. Nat Rev Nephrol. 2013; 9 (5): 255-265.

68. Vanmassenhove J, Kielstein J, Jörres A, Biesen WV. Management of patients at risk of acute kidney injury. Lancet. 2017; 389 (10084): 2139-2151.

69. Li Z, Wu M, Yao J, Guo J, Liao X, Song S et al. Caution on kidney dysfunctions of COVID-19 patients. medRxiv. 2020.
70. Ronco C, Reis T, De Rosa S. Coronavirus epidemic and extracorporeal therapies in intensive care: si vis pacem para bellum. Blood Purif [Internet]. 2020; 49 (3): 255-258. Available from: https://www.ncbi.nlm.nih.gov/pmc/articles/ PMC7179535/pdf/bpu-0049-0001.pdf

71. Sociedad Chilena de Medicina. Recomendaciones para el uso de terapias farmacológicas contra COVID-19 [Internet]. 2020. Disponible en: http://www.colegiomedico. cl/wp-content/uploads/2020/03/Consolidacion-TerapiaCOVID-19-FINAL.pdf.pdf.pdf.pdf

72. Basile C, Combe C, Pizzarelli F, Covic A, Davenport A, Kanbay $\mathrm{M}$ et al. Recommendations for the prevention, mitigation and containment of the emerging SARS-CoV-2 (COVID-19) pandemic in haemodialysis centres. Nephrol Dial Transplant. 2020; 35 (5): 737-741.

73. Ikizler TA. COVID-19 and dialysis units: what do we know now and what should we do? Am J Kidney Dis [Internet]. 2020; 76 (1): 1-3. Available from: https://reader.elsevier.com/ reader/sd/pii/S0272638620306089?token=E5F4A8BE5C5F 6B85B9C2C2133192DC96FCF7D36C10E5AEB67812FA05 OD6CCF4EBCE4BAD34B79B6BCA3E7A253FB1CF011

74. Leading European Nephrology. COVID-19 news and information [Internet]. 2020. Available from: https://www. era-edta.org/en/covid-19-news-and-information/

75. American Society of Transplantation. Coronavirus disease 2019 (COVID-19): Frecuently asked questions from transplant candidates and recipients [Internet]. 2020. Available from: https://www.myast.org/coronavirusdisease-2019-covid-19-frequently-asked-questionstransplant-candidates-and-recipients\#

76. Zheng Y, Lai W. Dermatology staff participate in fight against Covid-19 in China. J Eur Acad Dermatol Venereol [Internet]. 2020; 34 (5): e210-e211. Available from: https:// onlinelibrary.wiley.com/doi/pdf/10.1111/jdv.16390?casa_ token=nylNb2hVTm8AAAAA: GxAxV6wGLvOpUOHnK-va HKsSONE4DYrAnOKqQCdKzBiSc5RQ4CiM3KQf0BoovA yY8v1eDZGjVddsxcY

77. Recalcati S. Cutaneous manifestations in COVID-19: a first perspective. J Eur Acad Dermatol Venereol [Internet]. 2020; 34 (5): e212-e213. Available from: https:// onlinelibrary.wiley.com/doi/epdf/10.1111/jdv.16387

78. Joob B, Wiwanitkit V. COVID-19 can present with a rash and be mistaken for dengue. J Am Acad Dermatol [Internet]. 2020; 82 (5): e177. Available from: https://reader.elsevier.com/ reader/sd/pii/S0190962220304540?token=D1C915CCD23BA B4D5191A289CF1953691F2A8B36B6D25C327DDD9D140B D5D7ED9209CF5F432EE32D1AC00C46EC68DFE6

79. Hoenig LJ, Pereira FA. Rash as a clinical manifestation of COVID-19 photographs of a patient. Clin Dermatol [Internet]. 2020. Disponible en: https://doi.org/10.1016/j. clindermatol.2020.04.001

80. Mazzotta F, Troccoli T. Acute acro-ischemia in the child at the time of COVID-19. Eur J Pediat Dermatol [Internet]. 2020; 30 (2): 71-74.

81. Manalo IF, Smith MK, Cheeley J, Jacobs R. A dermatologic manifestation of COVID-19: transient livedo reticularis. J Am Acad Dermatol [Internet]. 2020; 83 (2): 700. Available from: https://reader.elsevier.com/reader/sd/pii/S01909622 20305582?token=26A7BF1E096BE97BC24613ED38B34 F5A07515905FB57EF7E36DB88C0EC03DCC91FBC106 A772ECF3B9EF5EE6C2841BCF9

82. Zhang $\mathrm{Y}$, Cao $\mathrm{W}$, Xiao M, Li YJ, Yang $\mathrm{Y}$, Zhao $\mathrm{J}$ et al. Clinical and coagulation characteristics of 7 patients 
Rev Latin Infect Pediatr 2020; 33 (s1): s10-s32

with critical COVID-2019 pneumonia and acro-ischemia. Zhonghua Xue Ye Xue Za Zhi [Internet]. 2020; 41 (0): E006. Available from: http://rs.yiigle.com/yufabiao/1186612.htm

83. Le Syndicat National des Dermatologues-Vénéréologues (SNDV) alerte sur les manifestations cutanées du COVID 19 [Internet]. Communiqué de presse. Le 6 avril 2020. Available from: https://www.syndicatdermatos.org/wpcontent/uploads/2020/04/cp-covid-peau-6-avril.pdf

84. Academia Española de Dermatología y Venereología. La AEDV colabora con el estudio COVID-Piel que se acaba de poner en marcha en España [Internet]. 2020. Disponible en: https://aedv.es/la-aedv-colabora-con-el-estudio-covidpiel-que-se-acaba-de-poner-en-marcha-en-espana/

85. Han H, Yang L, Liu R, Liu F, Wu KL, Li J et al. Prominent changes in blood coagulation of patients with SARSCoV-2 infection [Internet]. Clin Chem Lab Med. 2020; 58 (7): 1116-1120. Available from: https://www.degruyter. com/view/journals/cclm/ahead-of-print/article-10.1515cclm-2020-0188/article-10.1515-cclm-2020-0188. $\mathrm{xml}$ ?language $=\mathrm{en}$

86. Wang J, Hajizadeh N, Moore EE, McIntyre RC, Moore PK, Veress LA et al. Tissue plasminogen activator (tPA) treatment for COVID-19 associated acute respiratory distress syndrome (ARDS): a case series. J Thromb Haemost [Internet]. 2020; 18 (7): 1752-1755. Available from: https://onlinelibrary.wiley.com/doi/pdf/10.1111/jth.14828

87. Thachil J, Tang N, Gando S, Falanga A, Cattaneo M, Levi $\mathrm{M}$ et al. ISTH interim guidance on recognition and management of coagulopathy in COVID-19. J Thromb Haemost [Internet]. 2020; 18 (5): 1023-1026. Available from: https://onlinelibrary.wiley.com/doi/pdf/10.1111/ jth. 14810

88. Go YY, Kim Y, Cheon S, Nam S, Ku B, Kim M et al. SARS-CoV-2 and viral sepsis: observations and hypotheses. Hypothesis [Internet]. 2020; 395: 15171520. Available from: https://www.thelancet.com/action/ showPdf?pii=S0140-6736\%2820\%2930920-X

89. Álvarez-Hernández LF, Herrera-Almanza L. Disseminated intravascular coagulation: Relevant aspects for the diagnosis. Med Interna Mex. 2018; 34 (5): 735-745.

90. Squizzato A, Hunt BJ, Kinasewitz GT, Wada $H$, ten Cate $\mathrm{H}$, Thachil $\mathrm{J}$ et al. Supportive management strategies for disseminated intravascular coagulation: An international consensus. Thromb Haemost. 2016; 115 (5): 896-904.

91. Connors J, States U, Levy J, States U. COVID-19 and its implications for thrombosis and anticoagulation COVID-19 and its implications for thrombosis and anticoagulation. Blood [Internet]. 2020; 135 (23): 2033-2040. Available from: https://watermark.silverchair.com/bloodbld2020006000c. pdf?token=AQECAHi208BE49Ooan9kkhW_Ercy7Dm3ZL _9Cf3qfKAc485ysgAAA5YwggOSBgkqhkiG9w0BBwaggg ODMIIDfwIBADCCA3gGCSqGSIb3DQEHATAeBglghkgB ZQMEAS4wEQQMIdh6BiJ17AdXg5OnAgEQgIIDSQH3Ue kf0--OKqm1oviDuxBcdJ0P7WmvBOH

92. Gauna ME, Bernava JL. Recomendaciones diagnósticas y terapéuticas ante la respuesta inmune trombótica asociada a Covid-19 (RITAC) [Internet]. 2020. Disponible en: https://fundacionio.com/wp-content/uploads/2020/04/ Si\%CC\%81ndrome-RITAC.pdf.pdf.pdf.pdf.pdf.pdf.pdf

93. McGonagle D, Sharif K, O'Regan A, Bridgewood C. The role of cytokines including interleukin-6 in COVID-19 induced pneumonia and macrophage activation syndromelike disease. Autoimmun Rev [Internet]. 2020; 19 (6):
102537. Available from: https://www.researchgate.net/ publication/340266188_Interleukin-6_Use_in_COVID-19_ Pneumonia_Related_Macrophage_Activation_Syndrome

94. Moore JB, June $\mathrm{CH}$. Cytokine release syndrome in severe COVID-19. Science [Internet]. 2020; 368 (6490): 473474. Available from: https://science.sciencemag.org/ content/368/6490/473/tab-pdf

95. Gauna ME, Bernava JL. Recomendaciones diagnósticas y terapéuticas ante la respuesta inmune trombótica asociada a Covid-19 (RITAC). CorSalud. 2020; 12 (1): 60-63.

96. Zhang $Y$, Xiao $M$, Zhang $S$ et al. Coagulopathy and antiphospholipid antibodies in patients with Covid-19. N Engl J Med [Internet]. 2020; 382 (17): e38. Available from: https://www.nejm.org/doi/pdf/10.1056/NEJMc2007575

97. Newall F, Branchford B, Male C. Anticoagulant prophylaxis and therapy in children: current challenges and emerging issues. J Thromb Haemost. 2018; 16 (2): 196-208.

98. Baig AM, Khaleeq A, Ali U, Syeda H. Evidence of the COVID-19 virus targeting the CNS: tissue distribution, hostvirus interaction, and proposed neurotropic mechanisms. ACS Chem Neurosci [Internet]. 2020; 11 (7): 995-998. Available from: https://www.ncbi.nlm.nih.gov/pmc/articles/ PMC7094171/

99. Li YC, Bai WZ, Hashikawa T. The neuroinvasive potential of SARS-CoV2 may play a role in the respiratory failure of COVID-19 patients. J Med Virol. 2020; 92 (6): 552-555.

100. Turtle L. Respiratory failure alone does not suggest central nervous system invasion by SARS-CoV-2. J Med Virol [Internet]. 2020; 92 (7): 705-706. Available from: https:// onlinelibrary.wiley.com/doi/pdf/10.1002/jmv.25828

101. Ezpeleta D, García Azorín D. Manual COVID-19 para el neurólogo general [Internet]. San Sebastián de los Reyes, Madrid: Sociedad Española de Neurología; 2020. Disponible en: http://www.sen.es/attachments/article/2677/ Manual neuroCOVID-19 SEN.pdf

102. Dugue R, Cay-Martínez KC, Thakur KT et al. Neurologic manifestations in an infant with COVID-19. Neurology [Internet]. 2020; 94 (24): 1100-1102. Available from: https://n.neurology.org/content/neurology/ early/2020/05/18/WNL.0000000000009653.full.pdf

103. Jin $\mathrm{H}$, Hong $\mathrm{C}$, Chen S, Zhou $\mathrm{Y}$, Wang $\mathrm{Y}$, Mao L et al. Consensus for prevention and management of coronavirus disease 2019 (COVID-19) for neurologists. Stroke Vasc Neurol [Internet]. 2020; 5 (2): 146-151. Available from: https://svn.bmj.com/content/svnbmj/early/2020/05/07/svn2020-000382.full.pdf

104. Xu Z, Shi L, Wang $Y$ et al. Pathological findings of COVID-19 associated with acute respiratory distress syndrome. Lancet Respir Med [Internet]. 2020; 8 (4): 420-422. Available from: https://reader.elsevier.com/ reader/sd/pii/S221326002030076X?token $=85 \mathrm{~A} 1 \mathrm{~B} 05 \mathrm{DA}$ 737FFB7653E0FDF921C87960156C5A63A6C319DCC FCBE571983A846E524A235EA8F7E7849B9D7A8A220 7BFE

105. Tian S, Hu N, Lou J, Chen K, Kang X, Xiang Z et al. Characteristics of COVID-19 infection in Beijing. $J$ Infect. 2020; 80 (4): 401-416.

106. Mao L, Jin $H$, Wang $M$, Hu $Y$, Chen $S, H e Q$ et al. Neurologic manifestations of hospitalized patients with coronavirus disease 2019 in Wuhan, China. JAMA Neurol. 2020; 77 (6): 683-690.

107. Valderrama EV, Humbert K, Lord A, Frontera J, Yaghi S. Severe acute respiratory syndrome coronavirus 2 
infection and ischemic stroke. Stroke [Internet]. 2020; 51 (7): e124-e127. Available from: https://doi.org/10.1161/ STROKEAHA.120.030153

108. McAbee GN, Brosgol Y, Pavlakis S, Agha R, Gaffoor M. Encephalitis associated with COVID-19 infection in an 11 year-old child. Pediatric Neurology. Brooklyn, NY: Elsevier Inc.; 2020.

109. Moriguchi T, Harii N, Goto J, Harada D, Sugawara H. A first case of meningitis/encephalitis associated with SARSCoronavirus-2. Int J Infect Dis [Internet]. 2020; 94: 55-58. Available from: https://reader.elsevier.com/reader/sd/pii/S1 201971220301958?token=760D84E8F46C05B842665DC BEF1567F3422C8FA0A970B6187A8D88778E7971007E4 51A6E2C93D0CBB7484F73CE96403A

110. Poyiadji N, Shahin G, Noujaim D, Stone M, Patel S, Griffith B. COVID-19-associated acute hemorrhagic necrotizing encephalopathy: imaging features. Radiology [Internet]. 2020; 296 (2): E119-E120. Available from: https://pubs. rsna.org/doi/pdf/10.1148/radiol.2020201187

111. Sociedad Colombiana de Pediatría. Complicaciones neurológicas por COVID-19, en niños de Colombia [Internet]. 2020. Disponible en: https://scp.com.co/wpcontent/uploads/2020/04/comunicado-SCP-ASCONICOVID19.pdf

112. Finsterer J, Stollberger C. Causes of hypogeusia/hyposmia in SARS-CoV2 infected patients. J Med Virol [Internet]. 2020; 10.1002/jmv.25903. Available from: https:// onlinelibrary.wiley.com/doi/pdf/10.1002/jmv.25903

113. Cheng JL, Huang C, Zhang GJ, Liu DW, Li P, Lu CY et al. Epidemiological characteristics of novel coronavirus pneumonia in Henan. Chinese $\mathrm{J}$ Tuberc Respir Dis [Internet]. 2020; 1 (0): E027. Available from: http://rs.yiigle. com/yufabiao/1183298.htm

114. Jin $M$, Tong Q. Rhabdomyolysis as potential late complication associated with COVID-19. Emerg Infect Dis [Internet]. 2020; 26 (7): 1618-1620. Available from: https:// wwwnc.cdc.gov/eid/article/26/7/20-0445_article

115. Zhao H, Shen D, Zhou H, Liu J, Chen S. Guillain-Barré syndrome associated with SARS-CoV-2 infection: causality or coincidence? Lancet Neurol [Internet]. 2020; 19 (5): 383-384. Available from: https://www.thelancet.com/action/ showPdf?pii=S1474-4422\%2820\%2930109-5

116. Atri D, Siddiqi HK, Lang JP, Nauffal V, Morrow DA, Bohula EA. COVID-19 for the cardiologist: basic virology, epidemiology, cardiac manifestations, and potential therapeutic strategies. JACC Basic Transl Sci [Internet]. 2020; 5 (5): 518-536. Available from: https://reader. elsevier.com/reader/sd/pii/S2452302X20301571?token=7 49958327A5BD0A6700579CE08B5F80691AA4E668BB4 89B346FECEBEE64C7D9DA09B7A2D9123C8550A5A4A 6А36266B38

117. Lala A, Johnson KW, Januzzi JL, Russak AJ, Paranjpe I, Richter $\mathrm{F}$ et al. Prevalence and impact of myocardial injury in patients hospitalized with COVID-19 infection. J Am Coll Cardiol [Internet]. 2020; 76 (5): 533-546. Available from: https://www.onlinejacc.org/content/accj/early/2020/06/08/j. jacc.2020.06.007.full.pdf

118. Tavazzi G, Pellegrini C, Maurelli M, Belliato M, Sciutti F, Bottazzi A et al. Myocardial localization of coronavirus in COVID-19 cardiogenic shock. Eur J Heart Fail [Internet]. 2020; 22 (5): 911-915. Available from: https://onlinelibrary. wiley.com/doi/pdf/10.1002/ejhf.1828
119. Ho JS, Tambyah PA, Ho AF, Chan MY, Sia CH. Effect of coronavirus infection on the human heart: A scoping review. Eur J Prev Cardiol [Internet]. 2020; 27 (11): 11361148. Available from: https://journals.sagepub.com/doi/ pdf/10.1177/2047487320925965

120. Xiong TY, Redwood S, Prendergast B, Chen M. Coronaviruses and the cardiovascular system: acute and long-term implications. Eur Heart J [Internet]. 2020; 41 (19): 1798-1800. DOI: 10.1093/eurheartj/ehaa231

121. Cosyns B, Lochy S, Luchian ML, Gimelli A, Pontone G, Allard SD et al. The role of cardiovascular imaging for myocardial injury in hospitalized COVID-19 patients. Eur Heart J Cardiovasc Imaging. 2020; 21 (7): 709-714.

122. Chen C, Zhou Y, Wang DW. SARS-CoV-2: a potential novel etiology of fulminant myocarditis. Herz. 2020; 45 (3): 230-232.

123. Guzik TJ, Mohiddin SA, Dimarco A, Patel V, Savvatis K, Marelli-Berg FM et al. COVID-19 and the cardiovascular system: implications for risk assessment, diagnosis, and treatment options. Cardiovasc Res [Internet]. 2020; 116 (10): C1666-1687. Available from: DOI: 10.1093/cvr/cvaa106

124. Sanna G, Serrau G, Bassareo PP, Neroni P, Fanos V, Marcialis MA. Children's heart and COVID-19: Up-to-date evidence in the form of a systematic review. Eur J Pediatr [Internet]. 2020; 179 (7): 1079-1087. Available from: https://link.springer.com/content/pdf/10.1007/s00431-02003699-0.pdf

125. Barker PCA, Lewin MB, Donofrio MT et al. Specific considerations for pediatric, fetal, and congenital heart disease patients and echocardiography service providers during the 2019 novel coronavirus outbreak: council on pediatric and congenital heart disease supplement to the statement of the american society of echocardiography: endorsed by the Society of Pediatric Echocardiography and the Fetal Heart Society. J Am Soc Echocardiogr [Internet]. 2020; 33 (6): 658-665. Available from: https://www.ncbi. nlm.nih.gov/pmc/articles/PMC7144602/pdf/main.pdf

126. Belhadjer Z, Méot M, Bajolle F et al. Acute heart failure in multisystem inflammatory syndrome in children (MIS-C) in the context of global SARS-CoV-2 pandemic. Circulation [Internet]. 2020; 10.1161/CIRCULATIONAHA.120.048360. Available from: https://www.ahajournals.org/doi/ pdf/10.1161/CIRCULATIONAHA.120.048360

127. Cheung EW, Zachariah P, Gorelik M, Boneparth A, Kernie $S G$, Orange JS et al. Multisystem inflammatory syndrome related to COVID-19 in previously healthy children and adolescents in New York City. JAMA [Internet]. 2020; 324 (3): 294-296. Available from: https://jamanetwork.com/ journals/jama/fullarticle/2767207

128. Whittaker E, Bamford A, Kenny J, Kaforou M, Jones CE, Shah $P$ et al. Clinical characteristics of 58 children with a pediatric inflammatory multisystem syndrome temporally associated with SARS-CoV-2. JAMA [Internet]. 2020; 324 (3): 259-269. Available from: https://jamanetwork.com/ journals/jama/fullarticle/2767209

129. Son MBF. Pediatric inflammatory syndrome temporally related to covid-19. BMJ [Internet]. 2020; 369: m2123. Available from: https://www.bmj.com/content/bmj/369/bmj. m2123.full.pdf

Correspondencia:

Dra. Rosangela Del Razo Rodríguez

E-mail: rosangelarr@yahoo.com 